Document downloaded from:

http://hdl.handle.net/10251/141518

This paper must be cited as:

Quiles-Carrillo, L.; Montanes, N.; Sammon, C.; Balart, R.; Torres-Giner, S. (2018).

Compatibilization of highly sustainable polylactide/almond shell flour composites by reactive extrusion with maleinized linseed oil. Industrial Crops and Products. 111:878-888. https://doi.org/10.1016/j.indcrop.2017.10.062

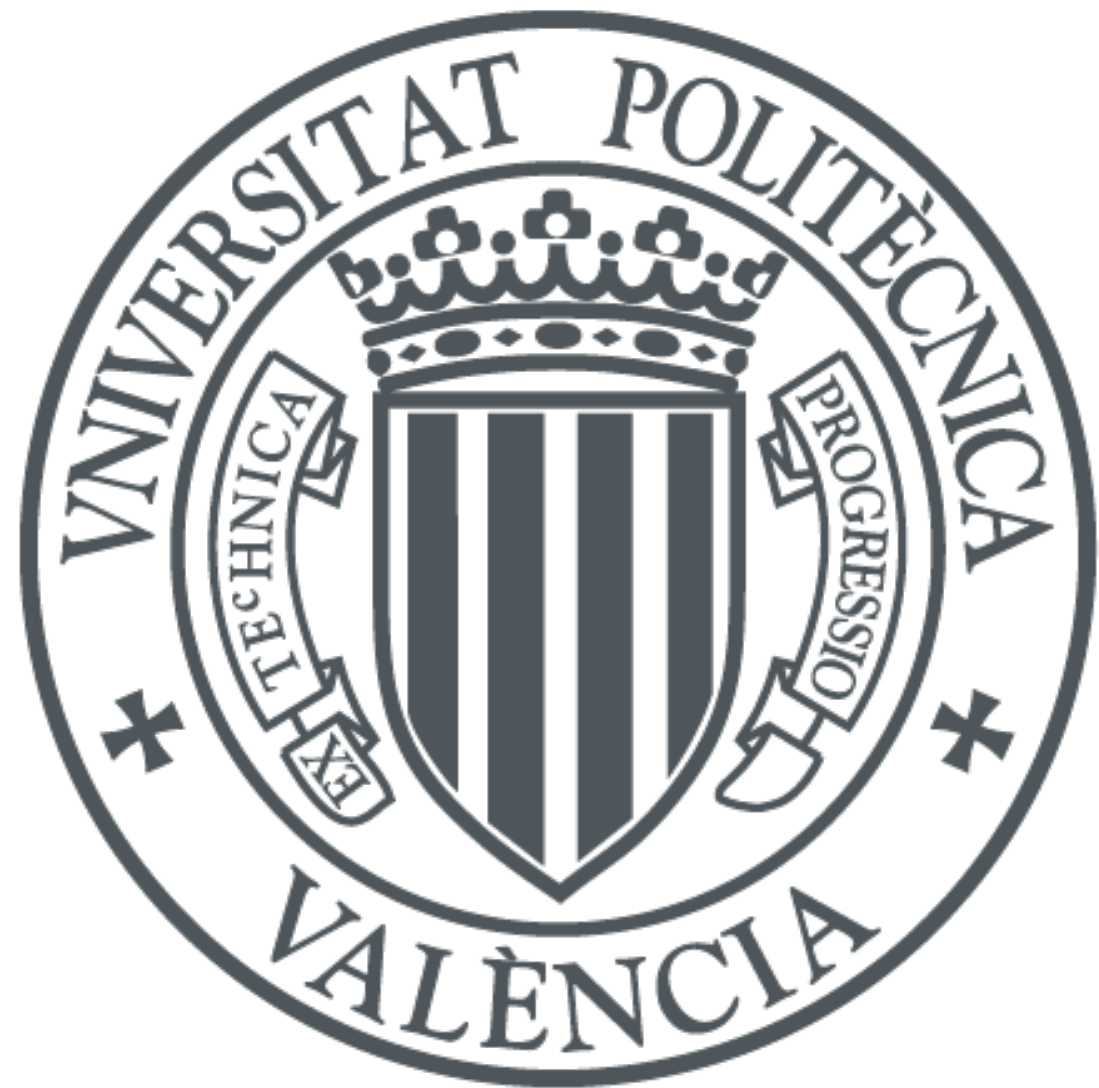

The final publication is available at

https://doi.org/10.1016/j.indcrop.2017.10.062

Copyright Elsevier

Additional Information 


\title{
Compatibilization of highly sustainable polylactide/almond husk flour composites by reactive extrusion with maleinized linseed oil
}

\author{
L. Quiles-Carrillo ${ }^{1}$, N. Montanes ${ }^{1}$, C. Sammon ${ }^{2}$, R. Balart ${ }^{1}$, S. Torres-Giner ${ }^{3,4^{*}}$ \\ ${ }^{1}$ Technological Institute of Materials (ITM), Universitat Politècnica de València (UPV), Alcoy, Spain \\ ${ }^{2}$ Materials and Engineering Research Institute, Sheffield Hallam University, Sheffield, UK. \\ ${ }^{3}$ Institute of Agrochemistry and Food Technology (IATA), Spanish National Research Council (CSIC), Paterna, Spain \\ ${ }^{4}$ School of Technology and Experimental Sciences (ESTCE), Universitat Jaume I (UJI), Castellón, Spain
}

Abstract. Green composites of polylactide (PLA) were produced by melt compounding with almond husk flour (AHF), a processed byproduct of the food industry, at a weight content of 30 wt.$\%$. However, due to the lack of miscibility between PLA and AHF, both raw materials obtained from crops, resultant composites presented poor ductility and low thermal stability. To overcome this limitation, maleinized linseed oil (MLO), a multi-functionalized plant-derived additive, was originally incorporated as a reactive compatibilizer during the extrusion process. Both chemical and physical characterization showed that 1-5 parts per hundred resin (phr) of MLO can successfully function as a compatibilizer on the PLA/AHF composites, leading to highly sustainable materials with balanced mechanical, thermal, and thermomechanical properties. Achieved compatibilization was particularly related to the dual effect of plasticization in combination with grafting, being based on the formation of new carboxylic ester bonds through the reaction of the multiple maleic anhydride groups present in MLO with the hydroxyl terminal groups of both PLA and cellulose of AHF. The here-described fully bio-based and biodegradable materials give an efficient sustainable solution to upgrade agro-food wastes as well as contribute to lower the cost of PLA-based materials.

Keywords: PLA, Cellulose, Multi-functionalized vegetable oils, Green composites, Reactive extrusion, Waste valorization

* Corresponding author:

Novel Materials and Nanotechnology Group, Institute of Agrochemistry and Food Technology (IATA), Spanish National Research Council (CSIC)

Calle Catedrático Agustín Escardino Benlloch 7, Paterna 46980 Spain

E-mail address: storresginer@iata.csic.es 


\section{Introduction}

Poly(lactic acid), or more correctly, polylactide (PLA), is a bio-based and biodegradable linear aliphatic polyester. Lactic acid, i.e., 2-hydroxypropionic acid, comprises its basic building block, which is in turn derived from the fermentation of starch sources (e.g., corn, potato, sugarcane, tapioca, etc.). To attain high molecular weights $\left(\mathrm{M}_{\mathrm{w}}\right)$, PLA is habitually prepared by ring-opening polymerization (ROP) of lactide, i.e., the six-membered cyclic diester of lactic acid, using tin octanoate as catalyst (Garlotta, 2001). PLA is nowadays considered the front runner in the emerging bioplastics market, showing an annual consumption of 140,000 tons (Madhavan Nampoothiri et al., 2010). This biopolyester is particularly interesting for short-term applications (e.g., food packaging) due to its two-fold environmental advantage of being obtained from renewable resources and being biodegradable, but durable applications can be also possible (Nagarajan et al., 2016). Physical properties of PLA are fairly similar to those of petrochemical-based polymers with high strength and low toughness such as polystyrene (PS) and poly(ethylene terephthalate) (PET) (Auras et al., 2010). Most common uses include disposable and compostable glasses for cold drinks, trays and rigid packages for foodstuff, teabags, lids, disposable plates, cutlery, etc (Lim et al., 2008). By using natural fillers (e.g., cellulosic materials) as reinforcement for PLA matrices, fully bio-based polymer composites can be manufactured (Johari et al., 2016; Oksman et al., 2003; Plackett et al., 2003; Yusoff et al., 2016). These constitute the so-called "green composites", which represent an emerging area in materials science and sustainable chemistry (La Mantia and Morreale, 2011).

Almond (Prunus amygdalus L.) is a very important crop throughout the world's temperate regions with an annual production of 2.31 million tons from a land area of 1.7 million hectare (Pirayesh et al., 2013). Almond husk is the ligno-cellulosic material forming the thick endocarp of the almond tree fruit. After harvesting, these woody shells are separated to obtain the edible seeds, often called almond meat, which are widely employed in the food industry. However, the husk remains available as a solid waste product for which no relevant industrial use has been developed to date 
(Esfahlan et al., 2010). Some novel applications of almond husk residues are being continuously proposed such as heavy metal adsorbents, dye absorbents, growing media, activated carbon preparation, and additives for the preparation of xylo-oligosaccharides (XOs) (Deniz, 2013; Doulati Ardejani et al., 2008; Ebringerová et al., 2007; Esfahlan et al., 2010; Urrestarazu et al., 2005). However, currently this is mainly incinerated (Chiou et al., 2016) or used as animal feed (Ledbetter, 2008). Additionally, it is worth to note that the processing byproducts, i.e., shells and hulls, account for more than $50 \%$ by dry weight of the almond fruit (Fadel, 1999). Consequently, it is estimated that around $0.8-1.7$ million tons of this residue are annually generated (Pirayesh and Khazaeian, 2012). Interestingly, almond husk is highly lignified, representing 30-38\% of dry weight (Martínez et al., 1995). As a result, these agro-food wastes are potential candidates to be applied as renewable fillers to reinforce polymer and biopolymer matrices. For this application, these should be previously ground and dried to obtain the almond husk flour (AHF).

Previous research on green composites based on AHF is not very extensive and it is limited to the use of urea-formaldehyde (UF) resin (Gürü et al., 2006; Pirayesh et al., 2013; Pirayesh and Khazaeian, 2012), epoxy resin (Chaudhary et al., 2013), polypropylene (PP) (Essabir et al., 2013b; Hosseinihashemi et al., 2016; Lashgari, 2013), polyvinyl chloride (PVC) (Crespo et al., 2007a; Crespo et al., 2007b), and poly(ع-caprolactone) (PCL) (Valdés et al., 2016; Valdés García et al., 2014). In relation to thermoplastic materials, these previous studies have shown that the incorporation of AHF can bring important advantages such as mechanical reinforcement, improved ecological character, and low costs. Besides intrinsic properties of each component, the mechanical and thermomechanical properties of the resultant green composites are dependent on filler aspect ratio, filler content and orientation, and on adhesion at the filler-matrix interface (Nagarajan et al., 2013). The latter, i.e., the interfacial filler-matrix adhesion, is crucial since it is responsible for promoting a good stress transfer from the continuous phase to the dispersed fillers that must carry the load. Nevertheless, the high hydrophilicity of cellulose-based fillers does not habitually present 
good adhesion with the hydrophobic or low hydrophilic polymers used as the composite matrix (Torres-Giner et al., 2017). Poor filler wetting causes a nonuniform distribution of fillers in the matrix consequently aggregation and void formation is habitually observed during melt processing. Many different approaches, reported in a number of recent reviews (Bledzki and Gassan, 1999; Bledzki et al., 1996; La Mantia and Morreale, 2011; Wei and McDonald, 2016), have explored different strategies to improve adhesion in cellulose-reinforced polymer materials. These methods mainly include filler surface modification prior to composite manufacture via chemical (e.g., esterification, etherification, treatment with silanes or isocyanates) or physical means (e.g., plasma, corona treatments, and radiation) as well as modification of the polymer matrix. Among them, the exposure to ultraviolet (UV) radiation has been recently demonstrated to be very effective on the activation of the filler surface in order to improve the physical properties of the resultant polymer composites (Torres-Giner et al., 2016b).

An alternative approach to improve fiber-matrix adhesion and fiber dispersion in polymer composites is the use of a compatibilizer, playing the role of adhesion promoter (Sengupta et al., 2013). In this sense, reactive extrusion (REX) is a well-known and cost-effective methodology to introduce a variety of functional groups into biopolymer chains (Miladinov and Hanna, 2000; Raquez et al., 2006). Based on this concept, REX has been recently proposed as novel route for grafting inorganic nanoparticles to biopolymer matrices, which results in sustainable polymer nanocomposites with enhanced physical properties (Torres-Giner et al., 2016a). This is due to biopolyester chains are characterized by hydroxyl and carboxylic acid terminal groups, which can establish chemical interactions during melt processing. This process mainly involves the chemical attachment of the fillers to the biopolymer chains by the action of reactive molecules with two or more average functionalities $(f)$, i.e., with at least two functional sites. These bi- or multi-functional additives actually act as interfacial agents and improve adhesion between filler and the polymer continuous phase by the creation of covalent bonds. 
Maleinized linseed oil (MLO) is a natural cross-linker, industrially prepared from linseed oil that is extracted from oilseed flax (Linum usitatissimum L.). Maleinization process provides multiple anhydride functionalities in the structure of MLO, which could potentially react thereafter with hydroxyl groups (Ford et al., 2011; Ford et al., 2012). Additionally, small amounts of MLO can also act as a sustainable plasticizer for PLA-based materials, allowing chain motion and improving processing conditions, thermal stability, and ductility (Ferri et al., 2017). Moreover, the use of vegetable oils is of great interest from an environmental point of view as they further allow obtaining fully bio-based and compostable formulations (Garcia-Garcia et al., 2016). Based on recent research findings (Ferri et al., 2016), the present study reports the compatibilization by MLO of cellulosic AHF, obtained as a byproduct of the food industry, with PLA biopolymer. The influence of different contents of MLO on the thermal, mechanical, and morphological properties of these novel green composites is evaluated and related to its compatibilizing effect.

\section{Materials and methods}

\subsection{Materials}

The PLA used in this work was Ingeo ${ }^{\text {TM }}$ Biopolymer 3251D, supplied by NatureWorks (Minnetonka, USA). According to the manufacturer, this is an injection molding-grade resin made primarily from dextrose that is derived from field corn grown for industrial and functional end-uses.

The biopolymer has a $\mathrm{M}_{\mathrm{W}}$ of $5.5 \times 10^{4} \mathrm{~g} / \mathrm{mol}$, with a polydispersity index (PI) of 1.62, a melt flow rate (MFR) of $30-40 \mathrm{~g} / 10 \mathrm{~min}\left(190^{\circ} \mathrm{C}, 2.16 \mathrm{~kg}\right.$ ), and a density of $1.24 \mathrm{~g} / \mathrm{cm}^{3}$. Almond (Prunus amygdalus L.) was collected in the Sierra Mariola region and its husk was provided by Jesol Materias Primas S.A. (Valencia, Spain) as an industrial byproduct after seed extraction. MLO was obtained from Vandeputte (Mouscron, Belgium) as VEOMER LIN. This agent has a viscosity of $1,000 \mathrm{cP}\left(20^{\circ} \mathrm{C}\right)$ and an acid value of $105-130 \mathrm{mg}$ potassium hydroxide $(\mathrm{KOH}) / \mathrm{g}$.

\subsection{Reactive extrusion}


As-received almond husk was ground in a Retsch GmbH (Düsseldorf, Germany) SK 100 Cross Beater mill at a rotating speed of $10,000 \mathrm{rpm}$. Resultant ground particles were sieved using a Cisa ${ }^{\circledR}$ Sieve Shaker model RP09 (Barcelona, Spain) to select a homogenous particle size distribution with a top-cut of $150 \mu \mathrm{m}$. Figure 1 shows the almond husk and the obtained AHF in powder form. Subsequently, AFH was UV irradiated for 4 min in a Honle UV Technology (Barcelona, Spain) UVASPOT 1000RF2 cabinet, based on previous research (Torres-Giner et al., 2016b), using a high pressure mercury lamp with a power of $1000 \mathrm{~W}$ at a wavelength at $350 \mathrm{~nm}$.

Prior to processing, to remove any residual moisture, the biopolymer pellets and AHF powder were stored at $60^{\circ} \mathrm{C}$ for $36 \mathrm{~h}$ in an Industrial Marsé (Barcelona, Spain) dehumidifying dryer MD. The final water content was kept in the range 1-2\%. A constant weight percentage of $30 \mathrm{wt} .-\%$ of AHF was used to evaluate the influence of MLO on the measured physical properties. This composite composition was selected based on previous reported results observed for PLA green composites (Balart et al., 2016b). The MLO range composition was subsequently varied in the range of 0-10 parts per hundred resin (phr) since previous studies with vegetable oils indicated saturation with contents below $10 \mathrm{phr}$ (Balart et al., 2016a). Table 1 summarizes the set of prepared green composites.

Extrusion was performed on a twin-screw co-rotating extruder ZSK-18 MEGAlab from Coperion (Stuttgart, Germany). The screws feature $18 \mathrm{~mm}$ diameter with a length (L) to diameter (D) ratio, i.e., $\mathrm{L} / \mathrm{D}$, of 48 . The materials dosage was set to achieve a residence time of about $1 \mathrm{~min}$, based on previously described configuration (Torres-Giner et al., 2016a), in which the AHF powder was fed into a ZS-B 18 twin-screw side feeder from K-Tron (Pitman, USA) while MLO was added through a loss-in-weight (LIW) liquid feeder FDDW-MD2-DKMP-6 from Brabender Technologie GmbH (Duisburg, Germany). The screws speed was fixed at $300 \mathrm{rpm}$ and the temperature profile, from the hopper to the die, was set as follows: $170-180-180-180-190-190-190^{\circ} \mathrm{C}$. The extruded material was cooled in a water bath and pelletized using an air-knife unit. 


\subsection{Injection molding}

Green composite pellets were shaped by injection molding in a Meteor 270/75 from Mateu \& Solé (Barcelona, Spain) for characterization. The profile temperature, from the feeding zone to the injection nozzle, was set as follows: $170-175-180-185^{\circ} \mathrm{C}$. A clamping force of 75 tons was applied. The cavity filling and cooling time were set at 1 and $10 \mathrm{~s}$, respectively. Standard samples with a thickness of $4 \mathrm{~mm}$ were obtained.

\subsection{Microscopy}

The morphology of the AHF particles and fracture surfaces of the green composites after the impact tests were observed by scanning electron microscope (SEM). An Oxford Instruments Zeiss Ultra 55 (Abingdon, UK) was used and an acceleration voltage of $2 \mathrm{kV}$ was applied. Samples surfaces were previously coated with a gold-palladium alloy in a Quorum Technologies Ltd EMITECH model SC7620 sputter coater (East Sussex, UK). AHF sizes were determined with Image J software.

\subsection{Infrared Spectroscopy}

Chemical analysis was performed via attenuated total reflection-Fourier transform infrared (ATRFTIR) spectroscopy. Spectra were recorded using a Bruker S.A. Vector 22 (Madrid, Spain) coupled to a PIKE MIRacle ${ }^{\mathrm{TM}}$ single reflection diamond ATR accessory (Madison, USA). Data were collected as the average of ten scans between 4000 and $400 \mathrm{~cm}^{-1}$ at a spectral resolution of $4 \mathrm{~cm}^{-1}$.

\subsection{Mechanical testing}

Injection-molded specimens with a dumbbell shape, a total length of $150 \mathrm{~mm}$, and a cross-section of $10 \times 4 \mathrm{~mm}^{2}$ were tested in a universal test machine ELIB 30 from S.A.E. Ibertest (Madrid, Spain). Tensile tests were performed according to ISO 527 . A $5 \mathrm{kN}$ load cell and a cross-head speed of 5 $\mathrm{mm} / \mathrm{min}$ were employed. Impact strength was tested on unnotched samples in a 1-J Charpy pendulum from Metrotec S.A. (San Sebastián, Spain), as suggested by ISO 179. Shore D hardness was determined in a durometer 676-D model from J. Bot S.A. (Barcelona, Spain) following ISO 
868. All specimens were tested in a controlled chamber at room conditions, i.e., $23^{\circ} \mathrm{C}$ and $50 \% \mathrm{RH}$. Six samples for each material were analyzed and averaged.

\subsection{Thermal analysis}

Thermal transitions of PLA and its green composites were conducted by differential scanning calorimetry (DSC) using a Mettler-Toledo, Inc. (Schwerzenbach, Switzerland) 821 model. For this, ca. $5 \mathrm{mg}$ samples were placed in $40 \mu \mathrm{l}$ hermetic aluminum sealed pans, previously calibrated with an indium standard. The analysis was performed in a dry reducing atmosphere in which nitrogen flowed at a constant rate of $66 \mathrm{~mL} / \mathrm{min}$. Samples were subjected to a two-step regime at a heating rate of $10{ }^{\circ} \mathrm{C} / \mathrm{min}$ to evaluate the thermal transitions. An initial heating cycle from 30 to $200^{\circ} \mathrm{C}$ was

followed by cooling down to $0^{\circ} \mathrm{C}$ at the same rate. The cold crystallization temperature $\left(\mathrm{T}_{\mathrm{cc}}\right)$, melting temperature $\left(\mathrm{T}_{\mathrm{m}}\right)$, enthalpy of melting $\left(\Delta \mathrm{H}_{\mathrm{m}}\right)$, and cold crystallization $\left(\Delta \mathrm{H}_{\mathrm{cc}}\right)$ were obtained from the heating scan while the crystallization temperature from the melt $\left(\mathrm{T}_{\mathrm{c}}\right)$ and enthalpy of crystallization $\left(\Delta \mathrm{H}_{\mathrm{c}}\right)$ were determined from the cooling scan. The percentage of crystallinity $\left(X_{c}\right)$ was determined using the following equation:

$$
\mathrm{Xc}=\left[\frac{\Delta \mathrm{Hm}-\Delta \mathrm{Hcc}}{\Delta \mathrm{H}_{\mathrm{m}}^{0} \cdot(1-\mathrm{w})}\right] \cdot 100
$$

where $\Delta \mathrm{H}_{\mathrm{m}}{ }^{0}=93.7 \mathrm{~J} / \mathrm{g}$ is the theoretical enthalpy corresponding to the melting of a $100 \%$ crystalline PLA sample (Torres-Giner et al., 2011), while the term 1-w represents the PLA weight fraction in the composite.

Thermogravimetric analysis (TGA) was used to evaluate the thermal stability of the materials using a TGA/SDTA 851 thermobalance from Mettler Toledo, Inc. (Schwerzenbach, Switzerland). The heating program was set from 30 to $650^{\circ} \mathrm{C}$ at a heating rate of $20^{\circ} \mathrm{C} / \mathrm{min}$ in nitrogen with a constant flow rate of $66 \mathrm{~mL} / \mathrm{min}$. Approximately $10 \mathrm{mg}$ of each sample was used for the measurements. The onset degradation temperature was defined as the temperature at $5 \%$ weight loss $\left(\mathrm{T}_{5 \%}\right)$ and the 
maximum rate degradation temperature $\left(\mathrm{T}_{\mathrm{deg}}\right)$ was obtained from the maximum value of the first derivative.

\subsection{Thermomechanical characterization}

Vicat softening point and heat deflection temperature (HDT) of the injection-molded pieces were both measured using a Metrotec S.A. (San Sebastián, Spain) DEFLEX 687-A2 standard Vicat/HDT station. Vicat softening point was determined following the UNE-EN 727 and ISO 306, in accordance with the B50 method. The protocol involved the placement of specimens in the testing apparatus so that the penetrating needle rested on its surface at least $1 \mathrm{~mm}$ from the edge. A load of $50 \mathrm{~N}$ was applied to the sample. This was then lowered into an oil bath in which the temperature was raised at a rate of $50{ }^{\circ} \mathrm{C} / \mathrm{h}$ until the needle penetrated $1 \mathrm{~mm}$. Measurements of HDT were carried out according to UNE-EN ISO 75-Method A and ASTM D648, using a heating rate of the medium (oil) of $120^{\circ} \mathrm{C} / \mathrm{h}$. A specimen of $80 \times 10 \times 4 \mathrm{~mm}^{3}$ was loaded in three-point bending in the edgewise direction with a distance of $60 \mathrm{~cm}$. The outer stress used for testing was 1.8 MPa and the temperature was increased at $120^{\circ} \mathrm{C} / \mathrm{h}$ until the sample deflected $0.31 \mathrm{~mm}$.

Dimensional stability was studied by determining the coefficient of linear expansion (CLTE) of PLA and its green composites using a thermomechanical analyzer (TMA) Q400 model from TA Instruments (Delaware, USA). The heating program was set between 0 and $140^{\circ} \mathrm{C}$ with a constant heating rate of $2{ }^{\circ} \mathrm{C} / \mathrm{min}$ and a constant load of $0.02 \mathrm{~N}$. The test was performed on injection-molded rectangular samples with dimensions of $40 \times 10 \times 4 \mathrm{~mm}^{2}$.

\section{Results}

\subsection{Morphology of fillers}

One of the most important adhesion mechanisms in polymer composites is mechanical interlocking, which is influenced by the filler shape. Figure 2a shows the morphology of the AHF powder determined via SEM. In this image a rough perimeter is observed, which can be a consequence of 
the crushing process due to the high hardness of this type of filler. A closer observation of the filler surface reveals the presence of some voids and grains. This unusual porous-like structure on the surface of almond husk contributes to its high degree of roughness. A similar morphology was previously reported for PVC-based composites (Crespo et al., 2007a; Crespo et al., 2007b), which was hypothesized to play a significant role in the adhesion with the polymer. The particle size histogram for AHF, determined from the SEM images, is shown in Figure $\mathbf{2 b}$. The predominant particle size is approximately $75 \mu \mathrm{m}$. Habitually this is another relevant parameter in the mechanical properties of green composites. Previous studies (Crespo et al., 2007a; Crespo et al., 2007b) also reported that mechanical impairment was much more pronounced in systems compromising large particles of AHF, i.e., in particular for those particle sizes greater than $150 \mu \mathrm{m}$. This effect is related to the arrangement of the fillers in the polymer matrix, which undoubtedly becomes more heterogeneous.

\subsection{Chemical properties}

Figure 3a shows the FTIR spectra of the AHF powder, MLO liquid, neat PLA, the unmodified PLA/AHF composite, and the PLA/AHF composite containing $2.5 \mathrm{phr}$ MLO.

The main bands of interest within each sample are described as follows. For AHF, the strongest absorption peak $\sim 1032 \mathrm{~cm}^{-1}$ is ascribed to the $\mathrm{C}-\mathrm{O}$ and $\mathrm{C}-\mathrm{OH}$ stretching vibrations of polysaccharide rings in cellulose (Liu et al., 2009). There is evidence of a broad absorption band between 3600 and $3000 \mathrm{~cm}^{-1}$, which corresponds to the characteristic $\mathrm{O}-\mathrm{H}$ stretching vibrations of hydrogen bonded of hydroxyl groups $(-\mathrm{OH})$ (Spinacé et al., 2009). Considering that the AHF particles were dried and exposed to UV radiation, these peaks should be mostly derived from - OH on the pyranose rings of cellulose (Lin and Dufresne, 2013), but the presence of small quantities of sorbed water cannot be excluded. The band centered at $1735 \mathrm{~cm}^{-1}$ represents the carbonyl $(\mathrm{C}=\mathrm{O})$ stretching (Doulati Ardejani et al., 2008). The low intense bands observed in the range 1400-1300 $\mathrm{cm}^{-1}$ are attributed to the bending vibrations of $\mathrm{C}-\mathrm{H}$ and $\mathrm{C}-\mathrm{O}$ groups of the polysaccharide ring 
(Olsson and Salmén, 2004). The absorbance band $\sim 1234 \mathrm{~cm}^{-1}$ corresponds to the $\mathrm{C}-\mathrm{O}-\mathrm{C}$ stretching vibration of the acetyl group in lignin and hemicellulose component, respectively (Doulati Ardejani et al., 2008; Essabir et al., 2013a).

Principal absorption bands for MLO are observed $\sim 3008 \mathrm{~cm}^{-1}$, which has been identified as the $=\mathrm{C}-$ $\mathrm{H}$ stretching of the carbon-carbon double bonds, $\sim 2924 \mathrm{~cm}^{-1}$ antisymmetric and $\sim 2853 \mathrm{~cm}^{-1}$ symmetric C-H stretching of the saturated carbon-carbon (C-C) bonds (Gomez et al., 2011). Other main bands can be observed $\sim 1742 \mathrm{~cm}^{-1}$ and $1708 \mathrm{~cm}^{-1}$ associated with the $\mathrm{C}=\mathrm{O}$ stretching of the carbonyl functionalities from the ester and maleic anhydride groups respectively, at $1161 \mathrm{~cm}^{-1}$ for the $\mathrm{C}-\mathrm{O}-\mathrm{C}, \mathrm{C}-\mathrm{O}$, and $\mathrm{C}-\mathrm{C}$ stretching of the ester functionalities, and at $719 \mathrm{~cm}^{-1}$ for the $\mathrm{C}-\mathrm{H}$ out of the plane stretching of the saturated C-C bonds (Gomez et al., 2011). Th band at centered $\sim 1458$ $\mathrm{cm}^{-1}$ is related to $\mathrm{C}-\mathrm{H}$ bending while peaks related to the anhydride groups can be seen as shoulders on the ester carbonyl $\sim 1810$ and $1777 \mathrm{~cm}^{-1}$.

One of the strongest peak of neat PLA spectrum appears at $1751 \mathrm{~cm}^{-1}$ and is assigned to $\mathrm{C}=\mathrm{O}$ stretching of the biopolymer (Paragkumar et al., 2006). Other strong bands observed are seen in between $1250-1050 \mathrm{~cm}^{-1}$, which arise from the ester $\mathrm{C}-\mathrm{O}$ and $\mathrm{C}-\mathrm{O}-\mathrm{C}$ stretching vibrations (TorresGiner et al., 2011). Bands in the range $1500-1300 \mathrm{~cm}^{-1}$ are assigned to symmetric and antisymmetric deformational vibrations of $\mathrm{C}-\mathrm{H}$ in the $\mathrm{CH}_{3}$ groups (Braun et al., 2006), in which the peak centered at $1450 \mathrm{~cm}^{-1}$ is related to $\mathrm{C}-\mathrm{H}$ bends from lactic acid moieties. The weak bands located at ca. 3000 and $2850 \mathrm{~cm}^{-1}$ are assigned to the antisymmetric and symmetric stretching vibrations of $-\mathrm{CH}_{2}$ (Braun et al., 2006). Incorporation of AHF certainly disrupts the $\mathrm{C}-\mathrm{H}$ vibrations (see subtle changes in the regions 3000-2850 and 1500-1300 $\mathrm{cm}^{-1}$ ) of the biopolymer backbone chain, but it does not produce further significant changes in the spectrum of PLA.

Interestingly, the addition of MLO produces additional changes with regard to the uncompatibilized PLA/AHF composite. One can observe in Figure $\mathbf{3 b}$ the formation of a shoulder in the carbonyl peak of PLA at approximately $1690 \mathrm{~cm}^{-1}$. This can be related to the $\mathrm{C}=\mathrm{O}$ stretching group of 
hydrolyzed anhydride groups of MLO in the green composite (Wu and Su, 1991). There is another weak increased absorption band in the range $1780-1850 \mathrm{~cm}^{-1}$ that can be ascribed to the symmetric stretching and asymmetric stretching of $\mathrm{C}=\mathrm{O}$ of remaining cyclic maleic anhydride groups (John et al., 1997; Zhu et al., 2012). The presence of new weak peaks in the region $3600-3300 \mathrm{~cm}^{-1}$ can be further attributed to $\mathrm{O}-\mathrm{H}$ stretch of the newly formed free carboxylic acid and may also indicate the presence of sorbed water in the green composite due to the presence of AHF. This is in agreement with Eren et al. (Eren et al., 2003) who observed a new carbonyl band of the carboxylic acid at $1709 \mathrm{~cm}^{-1}$ and a broad carboxylic $\mathrm{O}-\mathrm{H}$ centered at $3286 \mathrm{~cm}^{-1}$ during the polyesterification reaction of diols with MSO. Additionally, the formation of two new bands at $\sim 1560$ and $1518 \mathrm{~cm}^{-1}$, which are most likely to be derived from the antisymmetric stretches of delocalized deprotonated carboxylic acid end groups, can be produced as a result of interaction with sorbed water (Cabaniss et al., 1998). The symmetric stretch of these newly formed functional groups, expected to appear close to $1350 \mathrm{~cm}^{-1}$, are not explicitly visible to permit verification of this hypothesis due to the proximity of C-H band associated with PLA. Nevertheless it is clear that the incorporation of MLO in the green composite perturbs the band shape at the peak $\sim 1360 \mathrm{~cm}^{-1}$ and formation of these delocalized carboxyl groups would readily explain this phenomenon.

These FTIR results suggest that new esters and carboxylic acids are produced after addition of MLO to the green composites. The expected chemical reaction of MLO with PLA biopolymer and the cellulose component of AHF is given in Figure 4. This scheme proposes that carboxylic ester linkages are formed upon elevated temperature during melt processing. The MLO structure provides multiple chemical reaction sites, by the presence of a various number of maleic anhydride groups, giving therefore reliable bond strength for hydroxyl groups of both PLA end chains (and partially hydrolyzed PLA chains) and surface of AHF. As a result of the esterification reaction, a cellulose-grafted PLA (cellulose- $g$-PLA) structure is generated. 


\subsection{Mechanical properties of green composites}

Figure 5 shows the mechanical properties of the neat PLA and its green composites with varying the MLO content. Unreinforced PLA displays a tensile modulus and strength of 1960 and 63 MPa, respectively (Figure 5a and 5b). In addition, Shore D hardness is $\sim 79.6$ (Figure 5e). These values indicate that PLA is intrinsically an elastic and rigid material. Nevertheless, PLA is also brittle, showing a low elongation-at-break value of $5.3 \%$ and poor energy absorption with an impactstrength value of $15.7 \mathrm{~kJ} / \mathrm{m}^{2}$ (Figures 5c and 5d). Filling PLA with 30 wt.-\% AHF leads to a considerable decrease in mechanical properties, particularly for those related to material cohesion such as tensile strength, elongation at break, and impact strength. In particular, tensile modulus and strength are reduced to 1520 and $18 \mathrm{MPa}$, respectively (Figures 5a and 5b). Elongation at break is also reduced to $2.5 \%$ and impact strength to $7 \mathrm{~kJ} / \mathrm{m}^{2}$ (Figures $\mathbf{5 c}$ and $\mathbf{5 d}$ ), which represents an overall percentage reduction of approximately $55 \%$ in the mechanical ductility with regard to unfilled PLA. As a positive effect, the filler addition contributes to a slight increase in Shore D hardness of 84.7 , i.e., about $7 \%$ (Figure 5e). Similar mechanical results have been recently observed for other PLA-based green composites in which impact absorbed energy was reduced about $40 \%$ and Shore D hardness increased $9 \%$ by the presence of $30 \mathrm{wt} .-\%$ of hazelnut shell flour (HSF) (Balart et al., 2016b). Here, reported results clearly confirm the lack of compatibility between the PLA matrix and AHF.

As an efficient plasticizer, MLO remarkably improves the ductility of the green composites. Elongation-at-break values gradually increase up to $9.8 \%$, for green composites containing 5 phr MLO, i.e., an increase of about $292 \%$ and $84 \%$ in relation to the uncompatibilized green composite and to the neat PLA, respectively (Figure 5c). This is due to the strong plasticization effect of MLO on the PLA matrix, where the molecules posit among the polymer chains acting as a lubricant with an enhanced effect on chain mobility (Chieng et al., 2014). MLO can also move into the free volume of the green composite, improving its impact-absorbed energy. Therefore, incorporation of $5 \mathrm{phr}$ MLO increases the impact-strength value up to $12.1 \mathrm{~kJ} / \mathrm{m}^{2}$ (Figure 5d), which represents a 
percentage increase of about $73 \%$ with regard to unmodified PLA/AHF composite. In relation to the Shore D hardness, MLO contents of 2.5 and $5 \mathrm{phr}$ present similar values than the unmodified composite, i.e., 84.4 and 83.9, respectively, which can be regarded as a positive effect too (Figure 5e). However, for the highest MLO contents, i.e., 7.5 and $10 \mathrm{phr}$, it is observed an overall decrease in the mechanical properties. This indicates that saturation is achieved from $7.5 \mathrm{phr}$ MLO and subsequently phase separation occurs in the green composite (Ferri et al., 2016).

Both the increase in elongation at break and impact strength indicate that the addition of MLO leads to more ductile green composites, which can be explained by the previously described plasticization effect. Interestingly, the addition of MLO in the range of 1-5 phr MLO also leads to a noticeable increase in the tensile strength of the PLA/AHF composites. For instance, incorporation of $2.5 \mathrm{phr}$ MLO shows a tensile strength value of $40.1 \mathrm{MPa}$ (Figure 5b), which represents an increase of $118 \%$ in comparison to the uncompatibilized green composite. For contents over $7.5 \mathrm{phr}$ MLO, a clear decrease in both mechanical strength and ductility is observed. This negative effect can be related to a phase separation of the vegetable oil in the green composite due to an excess of concentration. This suggests that an optimal and balanced performance from a mechanical perspective is achieved for MLO contents close to $5 \mathrm{phr}$. The here-reported improvement of both mechanical strength and ductility gives some evidences that, in addition to plasticization, a degree of grafting occurs. This supports the infrared data of the MLO-treated green composites in which ester bonds are observed being formed between the multiple maleic anhydride groups present in MLO with hydroxyl groups of both PLA and AHF. This results in an effective stress transfer from the biopolymer to the reinforcing fillers.

\subsection{Thermal properties of green composites}

Table 2 shows a summary of the main thermal parameters obtained by DSC and TGA for PLA and its green composites compatibilized with different amounts of MLO. As it can be seen in the table, PLA is characterized by a $\mathrm{T}_{\mathrm{g}}$ of $\sim 67^{\circ} \mathrm{C}$, a $\mathrm{T}_{\mathrm{m}}$ of $172^{\circ} \mathrm{C}$, and a degree of crystallinity $\sim 15 \%$. In 
addition, the biopolymer shows cold crystallization phenomenon with a $\mathrm{T}_{\mathrm{cc}}$ of approximately $111^{\circ} \mathrm{C}$. After incorporation of $\mathrm{AHF}$, the value of $\mathrm{T}_{\mathrm{m}}$ is reduced to $168.5^{\circ} \mathrm{C}$ and crystallinity is also decreased to $\sim 9 \%$. These results indicate that the presence of AHF can potentially disrupt the folding process of PLA chains, supporting the above-described infrared data, which avoids the formation of more perfect crystals. Although Hosseinihashemi et al. (Hosseinihashemi et al., 2016) has recently reported that $\mathrm{AHF}$ is capable of acting as a nucleating agent that increases the crystallization temperature of the resultant polymer composites, AHF could also interfere with the growing stage by which the overall crystallinity level of the composite is decreased.

For the MLO-treated green composites, the addition of MLO increases the degree of crystallinity. Interestingly, the MLO-treated composites show a significant reduction in $\mathrm{T}_{\mathrm{cc}}$. It is important to remark that only the addition of $1 \mathrm{phr}$ MLO leads to a significant decrease in $\mathrm{T}_{\mathrm{cc}}$ of around $12^{\circ} \mathrm{C}$ and a value of $X_{c}$ of $\sim 23 \%$. The presence of MLO in the green composites improves the compatibilization and subsequent dispersion of AHF in the PLA matrix, which contributes to fewer polymer-polymer interactions and favors the formation of PLA crystals (Chieng et al., 2014). In addition, as previously described, MLO can readily react with hydroxyl groups in both PLA end chains and at the cellulosic surface of AHF leading to a combined effect of grafting and chain extension. Alternatively, as expected, $\mathrm{T}_{\mathrm{g}}$ decreases as a function of the vegetable oil content. This is related to an overall increase in the PLA chain mobility. It can be considered that MLO, due to its low $\mathrm{M}_{\mathrm{w}}$ as well as good chemical affinity with the biopolymer, facilitates the reduction of secondary forces (e.g., hydrogen bonding, van der Waals forces, etc.) among the PLA chains by occupying intermolecular spaces and increasing the free volume.

As also demonstrated in Table 2, the evaluation of thermal stability of the unmodified green composite shows a downward shift in $\mathrm{T}_{\text {deg }}$ from $339.3^{\circ} \mathrm{C}$, for the neat PLA, to $308.6^{\circ} \mathrm{C}$. The unmodified green composite also began to degrade around $5^{\circ} \mathrm{C}$ lower, i.e., approximately $290^{\circ} \mathrm{C}$. Therefore, a significant decrease in the thermal stability of PLA is clearly noticeable with the 
incorporation of AHF. This fact is related to the relatively low thermal stability of AHF, which initiates degradation at $221.2^{\circ} \mathrm{C}$ and, one assumes, negatively contributes to the reduction of the global thermal stability of the green composite. Here the observed impairment is in agreement with previous studies concerning the thermal stability of AHF-based polymer composites (Essabir et al., 2013b; Hosseinihashemi et al., 2016; Valdés García et al., 2014). It has been specifically reported that the degradation of AHF initially occurs in the range $250-350^{\circ} \mathrm{C}$, which is assigned to the thermal decomposition of cellulose and lignin (Hosseinihashemi et al., 2016). Interestingly, the addition of MLO exerts a positive effect on the overall thermal stability of the green composites. Specifically, the onset degradation temperature, corresponding to $5 \%$ weight loss, is increased to values in the range of $305-300^{\circ} \mathrm{C}$ for the green composites compatibilized by the vegetable oil. The degradation temperature is also significantly increased in comparison to the unmodified green composite. In particular, $\mathrm{T}_{\mathrm{deg}}$ is delayed up to about $20^{\circ} \mathrm{C}$ for treated green composites with MLO. This remarkable increase in the thermal stability can be directly related to the chemical interaction achieved by MLO, due to the covalent links between the cellulosic filler and the biopolymer matrix and MLO provides a physical barrier that obstructs the removal of volatile products produced during decomposition. A similar positive effect on the thermal stability was recently reported for PLA and epoxidized palm oil (EPO) blends (Chieng et al., 2014; Silverajah et al., 2012). Indeed, Chieng et al. (Chieng et al., 2014) observed a remarkable increase of $40^{\circ} \mathrm{C}$ in the onset degradation of PLA incorporating 5 wt.-\% EPO.

\subsection{Thermomechanical properties of green composites}

Table 3 shows the values of Vicat softening temperature, HDT, and CLTE, which are representative parameters for the thermomechanical properties of the green composites. With regard to the Vicat softening temperature, the value of unfilled PLA is $56.2^{\circ} \mathrm{C}$ and this increases to $73.4^{\circ} \mathrm{C}$ after the addition of 30 wt.- $\%$ AHF. This is in agreement with previous studies conducted on PLA/HSF composites (Balart et al., 2016b). Interestingly, the incorporation of MLO also shows a 
considerable increase in the softening point, reaching a maximum value of $87.3^{\circ} \mathrm{C}$. This represents an increase of about 55\% in relation to the unfilled PLA and additionally supports the chemical interaction of AHF with the biopolymer. It is also worthy to indicate that the highest value is observed for the green composites containing $1 \mathrm{phr}$ MLO, which further confirms that higher amounts of vegetable oil plasticize the PLA matrix and therefore reduces the service temperature of the green composites. A similar trend is also observed for HDT, in which the highest value is obtained for green composites containing $2.5 \mathrm{phr}$ MLO. In particular, HDT is increased from 53.1 and $61.6{ }^{\circ} \mathrm{C}$ for the neat PLA and unmodified green composite, respectively, up to $63.6{ }^{\circ} \mathrm{C}$.

The effect of compatibilization of MLO on the green composites can be additionally detected by TMA. Table 3 also includes CLTE values, below and above $\mathrm{T}_{\mathrm{g}}$, which are indicative of the dimensional stability of the green composites. As it can be seen in the table, the linear expansion is lower in the range of temperatures below $\mathrm{T}_{\mathrm{g}}$, which are typically ascribed to restrictions in the biopolymer chain mobility. Comparison of CLTE values below $\mathrm{T}_{\mathrm{g}}$ shows that the incorporation of AHF reduces values from 79.1 to $64.4 \mu \mathrm{m} / \mathrm{m}^{\circ} \mathrm{C}$. This indicates that AHF reinforces the PLA matrix and improves the dimensional stability of the biopolymer. Similar findings have been recently described for PLA/HSF composites (Balart et al., 2016b). With regard to the evolution of CLTE in the compatibilized green composites, values increase with the MLO content and range from 63 to $81 \mu \mathrm{m} / \mathrm{m}^{\circ} \mathrm{C}$. This is in accordance with the plasticization effect provided by MLO, which facilitates chain mobility and increases free volume. The evolution of CLTE over $\mathrm{T}_{\mathrm{g}}$ follows a similar tendency, showing a change from $116.4 \mu \mathrm{m} / \mathrm{m}^{\circ} \mathrm{C}$, for the unmodified green composite, up to values of $152.6 \mu \mathrm{m} / \mathrm{m}^{\circ} \mathrm{C}$ for the green composite containing $10 \mathrm{phr}$ MLO. The plasticization is then more pronounced at higher temperatures. This is in agreement with previously prepared PLA-based green composites plasticized by epoxidized linseed oil (ELO) (Balart et al., 2016a). All green composites show higher dimensional stability than the neat PLA. This can be considered as a positive finding, facilitating the technical applications of PLA at elevated temperatures. 


\subsection{Morphology of green composites}

Figure 6 shows the SEM images of fracture surfaces of PLA and its green composites after the impact tests. Figure 6a, which corresponds to the uncompatibilized PLA/AHF composite, clearly illustrates the typical brittle fracture of the biopolymer with a smooth fracture surface due to nonexistent or very low plastic deformation. In addition, the lack of interaction between AHF and PLA is clearly detectable. This absence is evidenced by the presence of several voids, which correspond to the detached particles after impact. Some of these also show the marks of the AHF surface. This supports a recent finding that particle debonding was shown to be the main failure mechanism of cellulosic fillers in biopolymer matrices (Torres-Giner et al., 2017). This occurs due to the lack of adhesion or cohesion at the particle-matrix interface of the green composite. This morphological observation correlates satisfactorily with the previously described performance of the unmodified green composites in which the presence of AHF does not contribute to an improvement of the mechanical and thermal properties but it rather decreases them.

In Figures $\mathbf{6 b}$ to $\mathbf{6} \mathbf{f}$ the positive effect of MLO addition on the morphology of the green composite can be seen. Although it is possible to still detect some voids in the PLA matrix after the addition of $1 \mathrm{phr}$ MLO (Figure 6b), the presence of finely dispersed AHF particles into PLA indicates that MLO certainly improves compatibility. The addition of $2.5 \mathrm{phr}$ (Figure 6c) and 5 phr MLO (Figure 6d) clearly leads to an improvement of the particle-polymer continuity, which is subsequently responsible for reducing stress concentration phenomena and increasing load transfer from the polymer matrix to the filler. As the MLO content increases, the filler-matrix gap is reduced. Figure 6e shows the good dispersion of the AHF in the biopolymer matrix with a 7.5 phr MLO content. This image supports the hypothesis that the presence of MLO in the green composites leads to improved wettability of fillers. This can be confirmed by Figure $\mathbf{6}$ for the PLA/AHF composite containing $10 \mathrm{phr}$ MLO in which the fillers are intimately covered by the vegetable oil. It can be also observed the absence of gaps with the surrounding PLA, which points towards improved 
interfacial affinity. However, certain phase separation is detectable due to the MLO saturation, which in turn would be responsible for impairing the performance of the green composites.

\section{Conclusions}

The present study describes the compatibilization of PLA and AHF by the use of MLO during melt compounding. Addition of this environmentally friendly plasticizer derived from vegetable oil, at relatively low contents, i.e., 1-5 phr, successfully improves the mechanical, thermal, and thermomechanical properties of the green composites. The achieved compatibilization was ascribed to a dual effect provided by MLO of plasticization in combination with grafting. As supported by FTIR analysis, new ester bonds were formed during extrusion process between the multiple maleic anhydride groups of MLO with the hydroxyl groups found at the AHF surface and PLA chain ends. For PLA/AHF composites containing 7.5 and $10 \mathrm{phr}$ MLO an overall decrease in the physical properties occurred due to plasticizer saturation.

The results obtained in this study indicate that AHF, derived as a byproduct from the food industry, can be used to reinforce PLA due to the efficient compatibilization provided by the multi-functional reactivity of MLO. In general terms, MLO and other multi-functionalized vegetable oils can be regarded as an attractive additive to enhance compatibility in immiscible or low miscible systems based on biopolymers and green composites with polar groups. In addition, due to their natural origin, these derived vegetable oils offer an environmentally friendly solution to improve industrial formulations and can positively contribute to the development of sustainable polymer technologies.

\section{Acknowledgements}

This research was supported by the Ministry of Economy and Competitiveness (MINECO) program number MAT2014-59242-C2-1-R and AGL2015-63855-C2-1-R and Generalitat Valenciana (GV) program number GV/2014/008. L. Quiles-Carrillo wants to thank GV for financial support through a FPI grant (ACIF/2016/182) and the Spanish Ministry of Education, Culture, and Sports (MECD) for his FPU grant (FPU15/03812). 


\section{References}

Auras, R., Lim, L.-T., Selke, S.E.M., Tsuji, H., 2010. Poly(Lactic Acid): Synthesis, Structures, Properties, Processing, and Applications, in: Rafael Auras, L.-T.L., Susan E. M. Selke, Hideto Tsuji (Ed.). John Wiley \& Sons, Inc., Hoboken, New Jersey.

Balart, J.F., Fombuena, V., Fenollar, O., Boronat, T., Sánchez-Nacher, L., 2016a. Processing and characterization of high environmental efficiency composites based on PLA and hazelnut shell flour (HSF) with biobased plasticizers derived from epoxidized linseed oil (ELO). Composites Part B: Engineering 86, 168-177.

Balart, J.F., García-Sanoguera, D., Balart, R., Boronat, T., Sánchez-Nacher, L., $2016 b$. Manufacturing and properties of biobased thermoplastic composites from poly(lactid acid) and hazelnut shell wastes. Polymer Composites DOI: 10.1002/pc.24007.

Bledzki, A.K., Gassan, J., 1999. Composites reinforced with cellulose based fibres. Progress in Polymer Science 24, 221-274.

Bledzki, A.K., Reihmane, S., Gassan, J., 1996. Properties and modification methods for vegetable fibers for natural fiber composites. Journal of Applied Polymer Science 59, 1329-1336.

Braun, B., Dorgan, J.R., Dec, S.F., 2006. Infrared Spectroscopic Determination of Lactide Concentration in Polylactide: An Improved Methodology. Macromolecules 39, 9302-9310.

Cabaniss, S.E., Leenheer, J.A., McVey, I.F., 1998. Aqueous infrared carboxylate absorbances: aliphatic di-acids. Spectrochimica Acta Part A: Molecular and Biomolecular Spectroscopy 54, 449458.

Chaudhary, A.K., Gope, P.C., Singh, V.K., 2013. Effect of Almond Shell Particles on Tensile Property of Particleboard. Journal of Materials and Environmental Science 4, 109-112.

Chieng, B.W., Ibrahim, N.A., Then, Y.Y., Loo, Y.Y., 2014. Epoxidized vegetable oils plasticized poly(lactic acid) biocomposites: mechanical, thermal and morphology properties. Molecules 19, 16024-16038.

Chiou, B.-S., Valenzuela-Medina, D., Bilbao-Sainz, C., Klamczynski, A.P., Avena-Bustillos, R.J., Milczarek, R.R., Du, W.-X., Glenn, G.M., Orts, W.J., 2016. Torrefaction of almond shells: Effects of torrefaction conditions on properties of solid and condensate products. Industrial Crops and Products 86, 40-48.

Crespo, J.E., Balart, R., Sanchez, L., Lopez, J., 2007a. Mechanical behaviour of vinyl plastisols with cellulosic fillers. Analysis of the interface between particles and matrices. International Journal of Adhesion and Adhesives 27, 422-428.

Crespo, J.E., Sanchez, L., Parres, F., López, J., 2007b. Mechanical and morphological characterization of PVC plastisol composites with almond husk fillers. Polymer Composites 28, 71 77 .

Deniz, F., 2013. Dye removal by almond shell residues: Studies on biosorption performance and process design. Materials Science and Engineering: C 33, 2821-2826. 
Doulati Ardejani, F., Badii, K., Limaee, N.Y., Shafaei, S.Z., Mirhabibi, A.R., 2008. Adsorption of Direct Red 80 dye from aqueous solution onto almond shells: Effect of $\mathrm{pH}$, initial concentration and shell type. Journal of Hazardous Materials 151, 730-737.

Ebringerová, A., Hromádková, Z., Koštálová, Z., Sasinková, V., 2007. Chemical valorization of agricultural by-products: isolation and characterization of xylan-based antioxidants from almond shell biomass. BioResources 3, 60-70.

Eren, T., Küsefoğlu, S.H., Wool, R., 2003. Polymerization of maleic anhydride-modified plant oils with polyols. Journal of Applied Polymer Science 90, 197-202.

Esfahlan, A.J., Jamei, R., Esfahlan, R.J., 2010. The importance of almond (Prunus amygdalus L.) and its by-products. Food Chemistry 120, 349-360.

Essabir, H., Hilali, E., Elgharad, A., El Minor, H., Imad, A., Elamraoui, A., Al Gaoudi, O., $2013 a$. Mechanical and thermal properties of bio-composites based on polypropylene reinforced with Nutshells of Argan particles. Materials and Design 49, 442-448.

Essabir, H., Nekhlaoui, S., Malha, M., Bensalah, M.O., Arrakhiz, F.Z., Qaiss, A., Bouhfid, R., 2013b. Bio-composites based on polypropylene reinforced with Almond Shells particles: Mechanical and thermal properties. Materials and Design 51, 225-230.

Fadel, J.G., 1999. Quantitative analyses of selected plant by-product feedstuffs, a global perspective. Animal Feed Science and Technology 79, 255-268.

Ferri, J.M., Garcia-Garcia, D., Montanes, N., Fenollar, O., Balart, R., 2017. The effect of maleinized linseed oil as biobased plasticizer in poly(lactic acid)-based formulations. Polymer International DOI: 10.1002/pi.5329.

Ferri, J.M., Garcia-Garcia, D., Sánchez-Nacher, L., Fenollar, O., Balart, R., 2016. The effect of maleinized linseed oil (MLO) on mechanical performance of poly(lactic acid)-thermoplastic starch (PLA-TPS) blends. Carbohydrate Polymers 147, 60-68.

Ford, E.N.J., Mendon, S.K., Rawlins, J.W., Thames, S.F., 2011. Spectroscopic analysis of cotton treated with neutralized maleinized soybean oil. Journal of the American Oil Chemists' Society 88, 681-687.

Ford, E.N.J., Rawlins, J.W., Mendon, S.K., Thames, S.F., 2012. Effect of acid value on the esterification mechanism of maleinized soybean oil with cotton. Journal of Coatings Technology Research 9, 637-641.

Garcia-Garcia, D., Fenollar, O., Fombuena, V., Lopez-Martinez, J., Balart, R., 2016. Improvement of Mechanical Ductile Properties of Poly(3-hydroxybutyrate) by Using Vegetable Oil Derivatives. Macromolecular Materials and Engineering, DOI: 10.1002/mame.201600330.

Garlotta, D., 2001. A Literature Review of Poly(Lactic Acid). Journal of Polymers and the Environment 9, 63-84.

Gomez, N.A., Abonia, R., Cadavid, H., Vargas, I.H., 2011. Chemical and spectroscopic characterization of a vegetable oil used as dielectric coolant in distribution transformers. Journal of the Brazilian Chemical Society 22, 2292-2303. 
Gürü, M., Tekeli, S., Bilici, İ., 2006. Manufacturing of urea-formaldehyde-based composite particleboard from almond shell. Materials and Design 27, 1148-1151.

Hosseinihashemi, S.K., Eshghi, A., Ayrilmis, N., Khademieslam, H., 2016. Thermal analysis and morphological characterization of thermoplastic composites filled with almond shell flour/montmorillonite. BioResources 11, 6768-6779.

Johari, A.P., Mohanty, S., Kurmvanshi, S.K., Nayak, S.K., 2016. Influence of Different Treated Cellulose Fibers on the Mechanical and Thermal Properties of Poly(lactic acid). ACS Sustainable Chemistry \& Engineering 4, 1619-1629.

John, J., Tang, J., Yang, Z., Bhattacharya, M., 1997. Synthesis and characterization of anhydridefunctional polycaprolactone. Journal of Polymer Science Part A: Polymer Chemistry 35, 11391148 .

La Mantia, F.P., Morreale, M., 2011. Green composites: A brief review. Composites Part A: Applied Science and Manufacturing 42, 579-588.

Lashgari, A.E., Ayoub; Farsi, Mohammad, 2013. A Study on Some Properties of Polypropylene Based Nanocomposites Made Using Almond Shell Flour and Organoclay. Asian Journal of Chemistry 25, 1043-1049.

Ledbetter, C.A., 2008. Shell cracking strength in almond (Prunus dulcis [Mill.] D.A. Webb.) and its implication in uses as a value-added product. Bioresource Technology 99, 5567-5573.

Lim, L.T., Auras, R., Rubino, M., 2008. Processing technologies for poly(lactic acid). Progress in Polymer Science 33, 820-852.

Lin, N., Dufresne, A., 2013. Supramolecular Hydrogels from In Situ Host-Guest Inclusion between Chemically Modified Cellulose Nanocrystals and Cyclodextrin. Biomacromolecules 14, 871-880.

Liu, D., Han, G., Huang, J., Zhang, Y., 2009. Composition and structure study of natural Nelumbo nucifera fiber. Carbohydrate Polymers 75, 39-43.

Madhavan Nampoothiri, K., Nair, N.R., John, R.P., 2010. An overview of the recent developments in polylactide (PLA) research. Bioresource Technology 101, 8493-8501.

Martínez, J.M., Granado, J.M., Montané, D., Salvadó, J., Farriol, X., 1995. Fractionation of residual lignocellulosics by dilute-acid prehydrolysis and alkaline extraction: Application to almond shells. Bioresource Technology 52, 59-67.

Miladinov, V.D., Hanna, M.A., 2000. Starch esterification by reactive extrusion. Industrial Crops and Products 11, 51-57.

Nagarajan, V., Mohanty, A.K., Misra, M., 2013. Sustainable Green Composites: Value Addition to Agricultural Residues and Perennial Grasses. ACS Sustainable Chemistry \& Engineering 1, 325333.

Nagarajan, V., Mohanty, A.K., Misra, M., 2016. Perspective on Polylactic Acid (PLA) based Sustainable Materials for Durable Applications: Focus on Toughness and Heat Resistance. ACS Sustainable Chemistry \& Engineering 4, 2899-2916. 
Oksman, K., Skrifvars, M., Selin, J.F., 2003. Natural fibres as reinforcement in polylactic acid (PLA) composites. Composites Science and Technology 63, 1317-1324.

Olsson, A.-M., Salmén, L., 2004. The association of water to cellulose and hemicellulose in paper examined by FTIR spectroscopy. Carbohydrate Research 339, 813-818.

Paragkumar, N.T., Edith, D., Six, J.L., 2006. Surface characteristics of PLA and PLGA films. Applied Surface Science 253, 2758-2764.

Pirayesh, H., Khanjanzadeh, H., Salari, A., 2013. Effect of using walnut/almond shells on the physical, mechanical properties and formaldehyde emission of particleboard. Composites Part B: Engineering 45, 858-863.

Pirayesh, H., Khazaeian, A., 2012. Using almond (Prunus amygdalus L.) shell as a bio-waste resource in wood based composite. Composites Part B: Engineering 43, 1475-1479.

Plackett, D., Løgstrup Andersen, T., Batsberg Pedersen, W., Nielsen, L., 2003. Biodegradable composites based on L-polylactide and jute fibres. Composites Science and Technology 63, 12871296.

Raquez, J.-M., Degée, P., Nabar, Y., Narayan, R., Dubois, P., 2006. Biodegradable materials by reactive extrusion: from catalyzed polymerization to functionalization and blend compatibilization. Comptes Rendus Chimie 9, 1370-1379.

Sengupta, S., Ray, D., Mukhopadhyay, A., 2013. Sustainable Materials: Value-Added Composites from Recycled Polypropylene and Fly Ash Using a Green Coupling Agent. ACS Sustainable Chemistry \& Engineering 1, 574-584.

Silverajah, V.S.G., Ibrahim, N.A., Zainuddin, N., Yunus, W.M.Z.W., Hassan, H.A., 2012. Mechanical, Thermal and Morphological Properties of Poly(lactic acid)/Epoxidized Palm Olein Blend. Molecules 17, 11729.

Spinacé, M.A.S., Lambert, C.S., Fermoselli, K.K.G., De Paoli, M.-A., 2009. Characterization of lignocellulosic curaua fibres. Carbohydrate Polymers 77, 47-53.

Torres-Giner, S., Gimeno-Alcañiz, J.V., Ocio, M.J., Lagaron, J.M., 2011. Optimization of electrospun polylactide-based ultrathin fibers for osteoconductive bone scaffolds. Journal of Applied Polymer Science 122, 914-925.

Torres-Giner, S., Montanes, N., Boronat, T., Quiles-Carrillo, L., Balart, R., 2016a. Melt grafting of sepiolite nanoclay onto poly(3-hydroxybutyrate-co-4-hydroxybutyrate) by reactive extrusion with multi-functional epoxy-based styrene-acrylic oligomer. European Polymer Journal 84, 693-707.

Torres-Giner, S., Montanes, N., Fenollar, O., García-Sanoguera, D., Balart, R., $2016 b$. Development and optimization of renewable vinyl plastisol/wood flour composites exposed to ultraviolet radiation. Materials and Design 108, 648-658.

Torres-Giner, S., Montanes, N., Fombuena, V., Boronat, T., Sánchez-Nacher, L., 2017. Preparation and characterization of compression-molded green composite sheets made of poly(3hydroxybutyrate) reinforced with long pita fibers. Advances in Polymer Technology DOI: 10.1002/adv.21789. 
Urrestarazu, M., Martínez, G.A., Salas, M.d.C., 2005. Almond shell waste: possible local rockwool substitute in soilless crop culture. Scientia Horticulturae 103, 453-460.

Valdés, A., Fenollar, O., Beltrán, A., Balart, R., Fortunati, E., Kenny, J.M., Garrigós, M.C., 2016. Characterization and enzymatic degradation study of poly( $\varepsilon$-caprolactone)-based biocomposites from almond agricultural by-products. Polymer Degradation and Stability 132, 181-190.

Valdés García, A., Ramos Santonja, M., Sanahuja, A.B., Del Carmen Garrigós Selva, M., 2014. Characterization and degradation characteristics of poly( $\varepsilon$-caprolactone)-based composites reinforced with almond skin residues. Polymer Degradation and Stability 108, 269-279.

Wei, L., McDonald, A.G., 2016. A review on grafting of biofibers for biocomposites. Materials 9.

Wu, C.H., Su, A.C., 1991. Functionalization of ethylene-propylene rubber via melt mixing. Polymer Engineering \& Science 31, 1629-1636.

Yusoff, R.B., Takagi, H., Nakagaito, A.N., 2016. Tensile and flexural properties of polylactic acidbased hybrid green composites reinforced by kenaf, bamboo and coir fibers. Industrial Crops and Products 94, 562-573.

Zhu, R., Liu, H., Zhang, J., 2012. Compatibilizing Effects of Maleated Poly(lactic acid) (PLA) on Properties of PLA/Soy Protein Composites. Industrial \& Engineering Chemistry Research 51, 77867792. 
Table 1. Summary of weight compositions (wt.-\%) according to the content of polylactide (PLA), almond husk flour (AHF), and maleinized linseed oil (MLO). MLO is added as parts per hundred resin (phr) of PLA/AHF composite.

\begin{tabular}{lccc} 
& \multicolumn{2}{c}{ Percentage (wt.- \%) } & \multirow{2}{*}{ MLO (phr) } \\
\cline { 2 - 3 } Samples & PLA & AHF & \\
\hline PLA & 100 & - & - \\
PLA/AHF & 70 & 30 & 1.0 \\
PLA/AHF + MLO 1 phr & 70 & 30 & 2.5 \\
PLA/AHF + MLO 2.5 phr & 70 & 30 & 5.0 \\
PLA/AHF + MLO 5 phr & 70 & 30 & 7.5 \\
PLA/AHF + MLO 7.5 phr & 70 & 30 & 10.0
\end{tabular}


Table 2. Thermal properties of polylactide (PLA) and its green composites with almond husk flour (AHF) with varying amounts of maleinized linseed oil (MLO). MLO content is expressed as parts per hundred resin (phr) of PLA/AHF composite. The glass transition temperature ( $\mathrm{T}_{\mathrm{g}}$ ), cold crystallization temperature $\left(\mathrm{T}_{\mathrm{cc}}\right)$, melting temperature $\left(\mathrm{T}_{\mathrm{m}}\right)$, normalized cold crystallization $\left(\Delta \mathrm{H}_{\mathrm{cc}}\right)$, and normalized enthalpy of melting $\left(\Delta \mathrm{H}_{\mathrm{m}}\right)$ are obtained from differential scanning calorimetry (DSC) curves during the second heating scan. The onset degradation temperature, defined as the temperature at $5 \%$ weight loss $\left(\mathrm{T}_{5 \%}\right)$, degradation temperature $\left(\mathrm{T}_{\mathrm{deg}}\right)$, and residual mass are obtained from the thermogravimetric analysis (TGA) curves. Residual mass is measured at $650^{\circ} \mathrm{C}$.

\begin{tabular}{|c|c|c|c|c|c|c|c|c|c|}
\hline \multirow{2}{*}{ Samples } & \multicolumn{6}{|c|}{ DSC parameters } & \multicolumn{3}{|c|}{ TGA parameters } \\
\hline & $\mathbf{T}_{\mathrm{g}}\left({ }^{\circ} \mathrm{C}\right)$ & $\mathbf{T}_{\mathrm{cc}}\left({ }^{\circ} \mathbf{C}\right)$ & $\mathbf{T}_{\mathrm{m}}\left({ }^{\circ} \mathrm{C}\right)$ & $\Delta \mathbf{H}_{\mathrm{cc}}(\mathrm{J} / \mathrm{g})$ & $\Delta H_{m}(J / g)$ & $\mathbf{X}_{\mathrm{c}}(\%)$ & $\mathbf{T}_{5 \%}\left({ }^{\circ} \mathbf{C}\right)$ & $\mathbf{T}_{\operatorname{deg}}\left({ }^{\circ} \mathrm{C}\right)$ & Residual mass (\%) \\
\hline $\mathrm{AHF}$ & - & - & - & - & - & - & $221.2 \pm 0.3$ & $259.2 \pm 0.5$ & $1.1 \pm 0.2$ \\
\hline PLA & $66.7 \pm 0.3$ & $111.3 \pm 0.3$ & $172.1 \pm 0.4$ & $21.1 \pm 0.3$ & $35.1 \pm 0.3$ & $14.9 \pm 0.3$ & $295.0 \pm 0.5$ & $339.3 \pm 0.5$ & $0.5 \pm 0.2$ \\
\hline PLA/AHF & $58.1 \pm 0.3$ & $110.1 \pm 0.1$ & $168.5 \pm 0.5$ & $22.6 \pm 0.3$ & $28.6 \pm 0.3$ & $9.1 \pm 0.2$ & $289.8 \pm 0.4$ & $308.6 \pm 0.4$ & $0.8 \pm 0.3$ \\
\hline PLA/AHF + MLO $1 \mathrm{phr}$ & $62.1 \pm 0.2$ & $96.9 \pm 0.3$ & $171.4 \pm 0.4$ & $17.1 \pm 0.2$ & $31.9 \pm 0.3$ & $22.8 \pm 0.3$ & $299.3 \pm 0.5$ & $322.1 \pm 0.3$ & $0.6 \pm 0.3$ \\
\hline PLA/AHF + MLO $2.5 \mathrm{phr}$ & $59.9 \pm 0.5$ & $103.6 \pm 0.3$ & $172.2 \pm 0.3$ & $17.3 \pm 0.4$ & $30.2 \pm 0.2$ & $20.2 \pm 0.3$ & $300.6 \pm 0.4$ & $322.2 \pm 0.4$ & $0.7 \pm 0.2$ \\
\hline PLA/AHF + MLO 5 phr & $58.7 \pm 0.3$ & $106.7 \pm 0.5$ & $171.9 \pm 0.3$ & $18.1 \pm 0.3$ & $29.7 \pm 0.4$ & $18.6 \pm 0.2$ & $301.2 \pm 0.5$ & $323.3 \pm 0.5$ & $0.6 \pm 0.3$ \\
\hline PLA/AHF + MLO $7.5 \mathrm{phr}$ & $55.2 \pm 0.2$ & $103.4 \pm 0.4$ & $171.9 \pm 0.4$ & $19.9 \pm 0.2$ & $27.5 \pm 0.3$ & $12.5 \pm 0.3$ & $302.2 \pm 0.4$ & $325.2 \pm 0.2$ & $0.7 \pm 0.3$ \\
\hline PLA/AHF + MLO $10 \mathrm{phr}$ & $54.9 \pm 0.3$ & $102.9 \pm 0.3$ & $172.3 \pm 0.3$ & $20.1 \pm 0.2$ & $27.4 \pm 0.2$ & $12.4 \pm 0.2$ & $304.3 \pm 0.3$ & $327.1 \pm 0.3$ & $0.7 \pm 0.2$ \\
\hline
\end{tabular}


Table 3. Vicat softening point, heat deflection temperature (HDT), and coefficient of linear thermal expansion (CLTE) below and above glass transition temperature $\left(\mathrm{T}_{\mathrm{g}}\right)$ for green composites of polylactide (PLA) with almond husk flour (AHF) with varying amounts of maleinized linseed oil (MLO). MLO content is expressed as parts per hundred resin (phr) of PLA/AHF composite.

\begin{tabular}{lcccc} 
Sample & Vicat $\left({ }^{\circ} \mathbf{C}\right)$ & HDT $\left({ }^{\circ} \mathbf{C}\right)$ & $\begin{array}{c}\text { CLTE below } \\
\mathbf{T}_{\mathbf{g}}\left(\boldsymbol{\mu m} / \mathbf{m}^{\circ} \mathbf{C}\right)\end{array}$ & $\begin{array}{c}\text { CLTE above } \\
\mathbf{T}_{\mathbf{g}}\left(\boldsymbol{\mu m} / \mathbf{m}^{\circ} \mathbf{C}\right)\end{array}$ \\
\hline PLA & $56.2 \pm 1.9$ & $53.1 \pm 1.0$ & $79.1 \pm 1.9$ & $170.9 \pm 1.9$ \\
PLA/AHF & $73.4 \pm 1.2$ & $61.6 \pm 0.4$ & $64.4 \pm 1.9$ & $116.4 \pm 1.9$ \\
PLA/AHF + MLO 1 phr & $87.3 \pm 1.8$ & $62.7 \pm 2.3$ & $63.3 \pm 1.9$ & $145.9 \pm 1.9$ \\
PLA/AHF + MLO 2.5 phr & $86.2 \pm 0.8$ & $63.6 \pm 2.5$ & $72.4 \pm 1.9$ & $146.8 \pm 1.9$ \\
PLA/AHF + MLO 5 phr & $81.9 \pm 1.8$ & $62.3 \pm 1.8$ & $73.8 \pm 1.9$ & $149.3 \pm 1.9$ \\
PLA/AHF + MLO 7.5 phr & $81.2 \pm 0.4$ & $61.3 \pm 1.9$ & $79.8 \pm 1.9$ & $151.1 \pm 1.9$ \\
PLA/AHF + MLO 10 phr & $81.3 \pm 2.9$ & $62.0 \pm 1.6$ & $81.0 \pm 1.9$ & $152.6 \pm 1.9$
\end{tabular}




\section{Figure Captions.}

Figure 1. (a) As-received almond husk; (b) Processed almond husk flour (AHF).

Figure 2. (a) Scanning electron microscope (SEM) image of almond husk flour (AHF). Image is taken with a magnification of 500x and a scale marker of $100 \mu \mathrm{m}$; (b) Histogram of AHF powder.

Figure 3. (a) Fourier transform infrared (FTIR) spectra, from bottom to top, of: Almond husk flour (AHF), maleinized linseed oil (MLO), polylactide (PLA), uncompatibilized PLA/AHF composite, and compatibilized PLA/AHF composite by 2.5 parts per hundred resin (phr) MLO. (b) Detail of the FTIR spectra for the uncompatibilized and compatibilized PLA/AHF composite. Arrows indicate the bands discussed in the text.

Figure 4. Schematic representation of the compatibilization between polylactide (PLA) with almond husk flour (AHF) by means of maleinized linseed oil (MLO).

Figure 5. Mechanical properties of polylactide (PLA) and its green composites with almond husk flour (AHF) varying the content of maleinized linseed oil (MLO) in terms of: (a) Tensile modulus; (b) Tensile strength at yield; (c) Elongation at break; (d) Charpy impact strength; (e) Shore D hardness. MLO content is expressed as parts per hundred resin (phr).

Figure 6. Scanning electron microscope (SEM) images of the fracture surfaces of: (a) Uncompatibilized polylactide (PLA)/almond husk flour (AHF) composite; (b) PLA/AHF composite compatibilized with 1 part per hundred resin (phr) maleinized linseed oil (MLO); (c) PLA/AHF composite compatibilized with 2.5 phr MLO; (d) PLA/AHF composite compatibilized with 5 phr MLO; (e) PLA/AHF composite compatibilized with $7.5 \mathrm{phr}$ MLO; (f) PLA/AHF composite compatibilized with $10 \mathrm{phr}$ MLO. Images are taken with a magnification of $1,500 \times$ and a scale marker of $10 \mu \mathrm{m}$. 


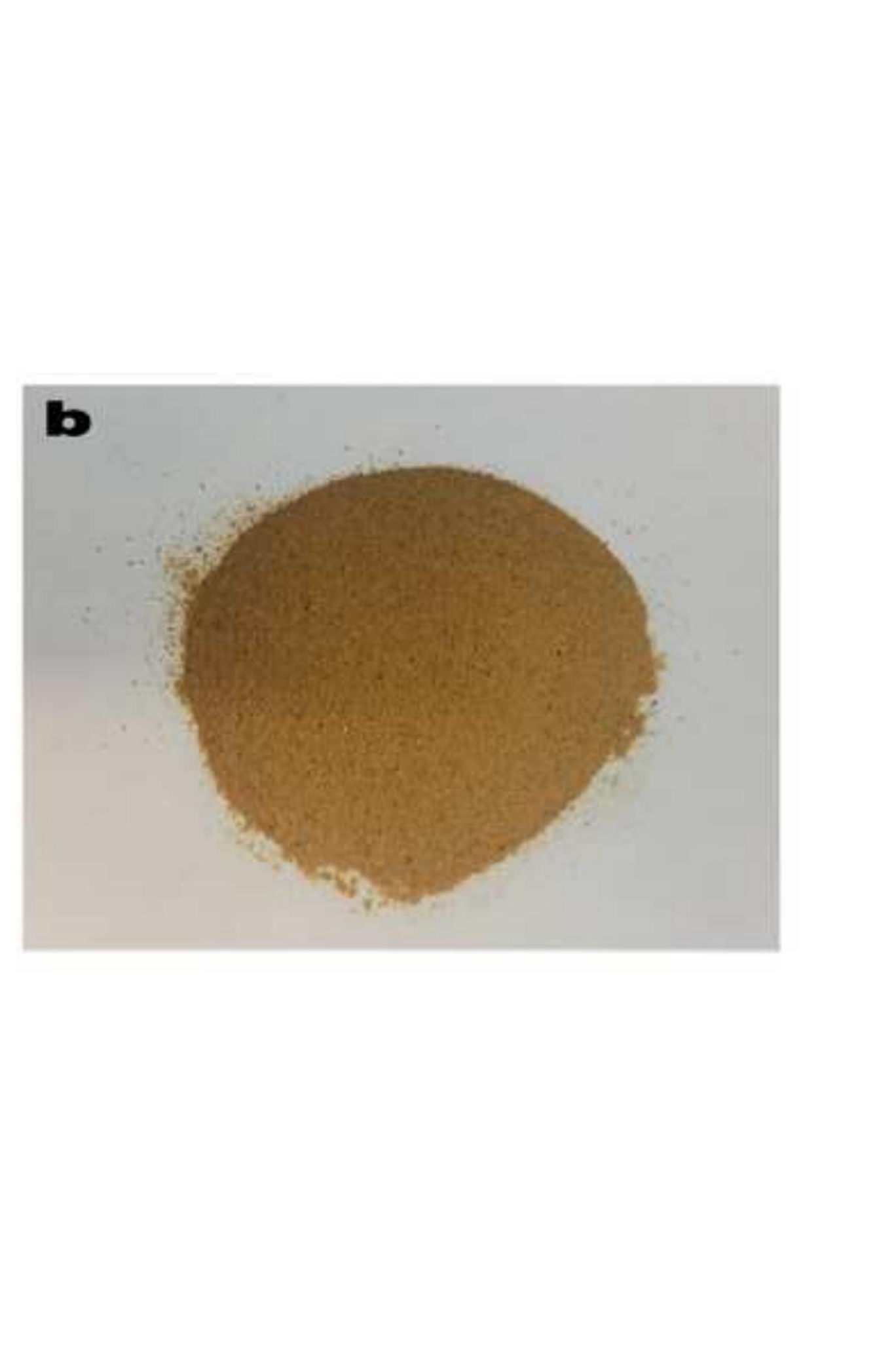

\section{Figure 1
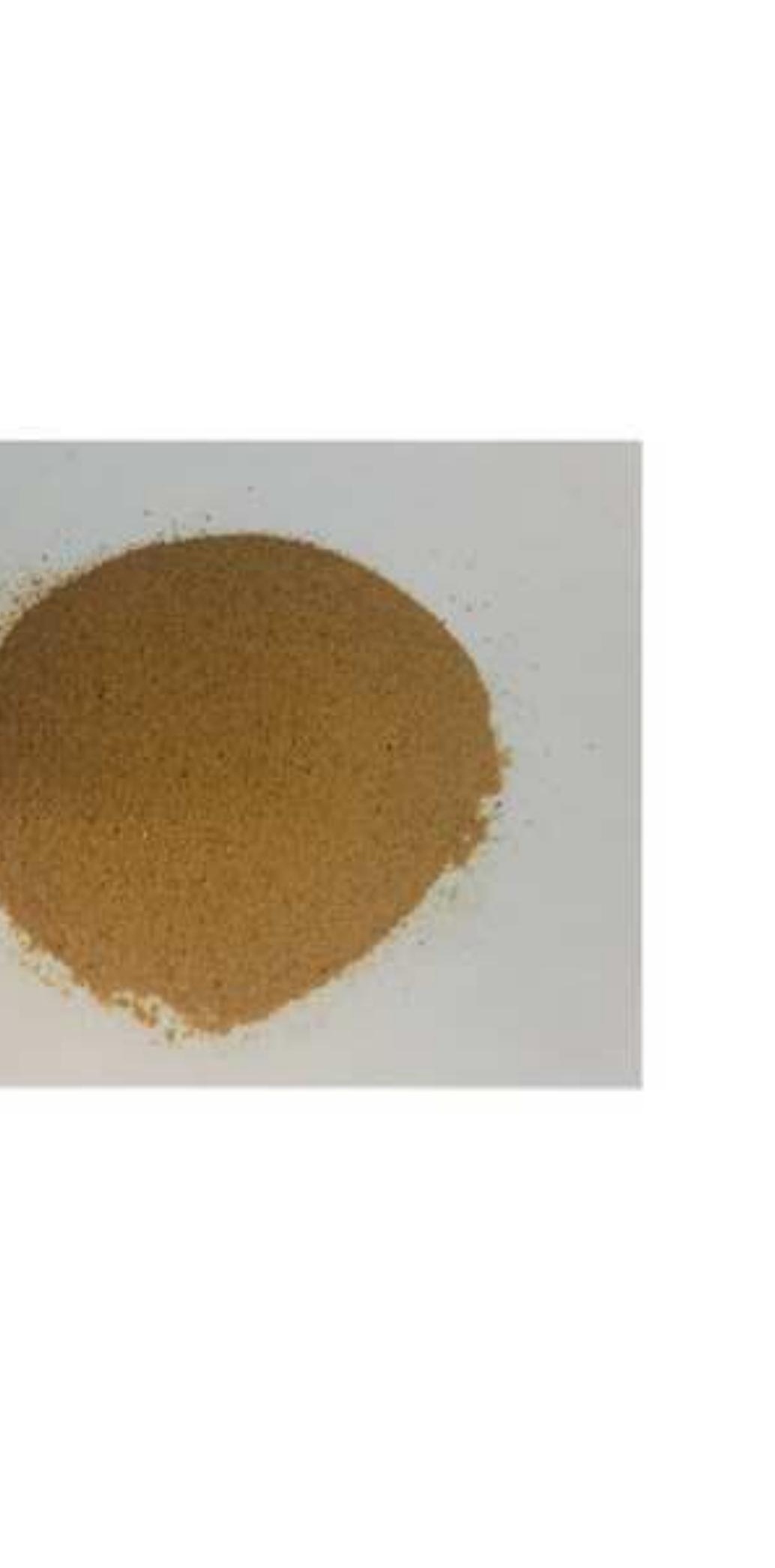
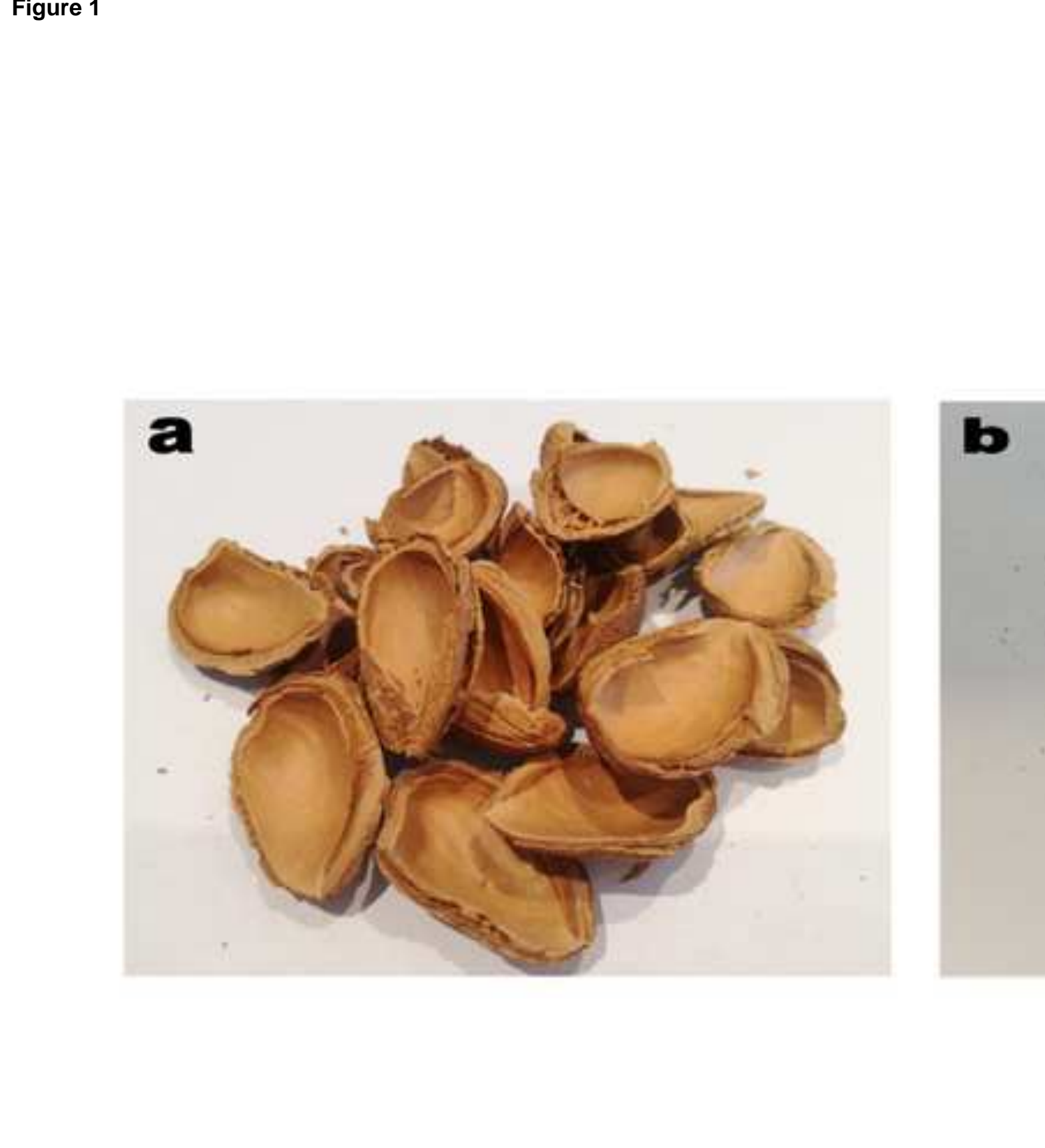
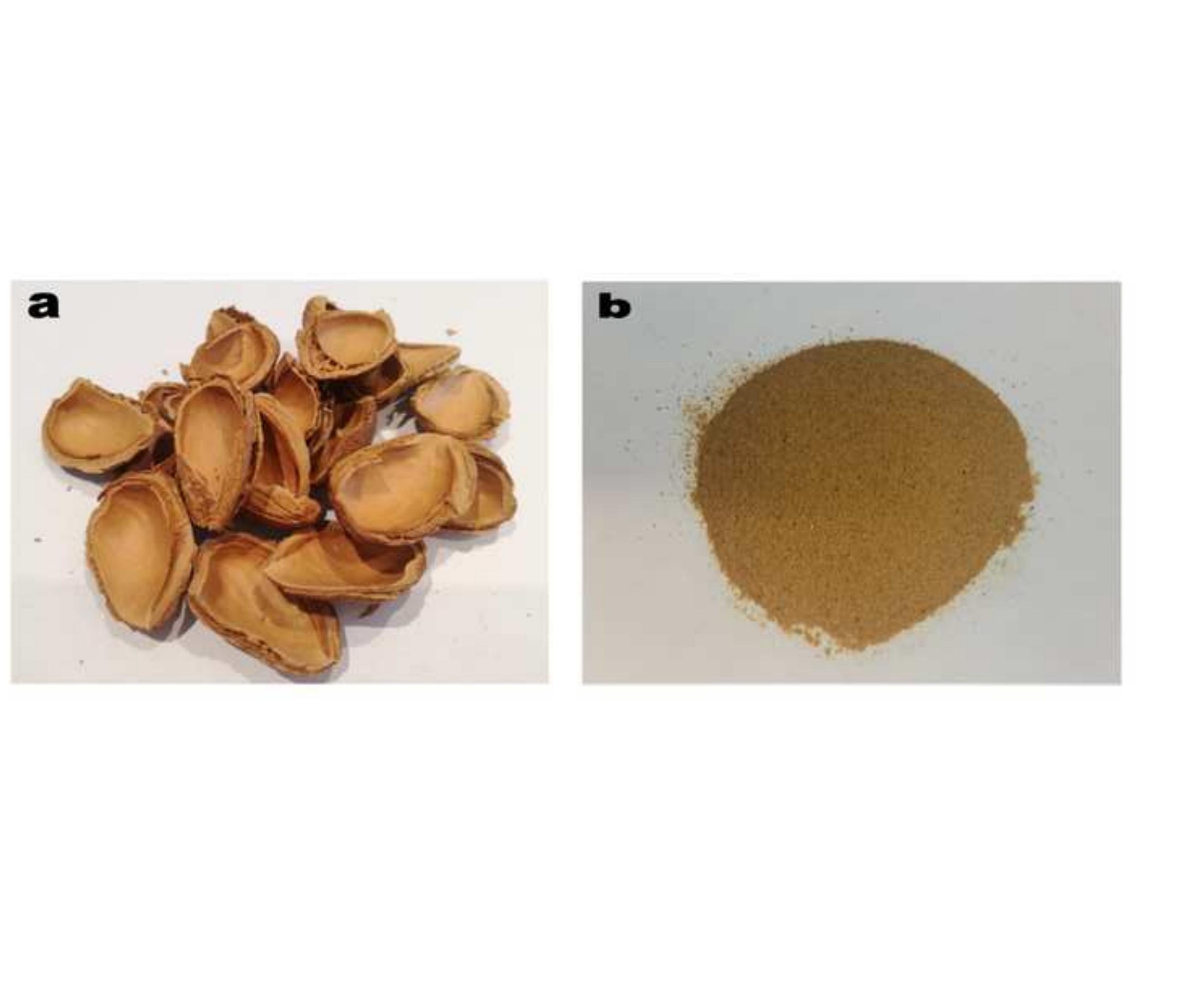

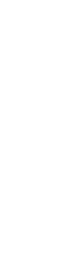

\section{.}

.

Pld 

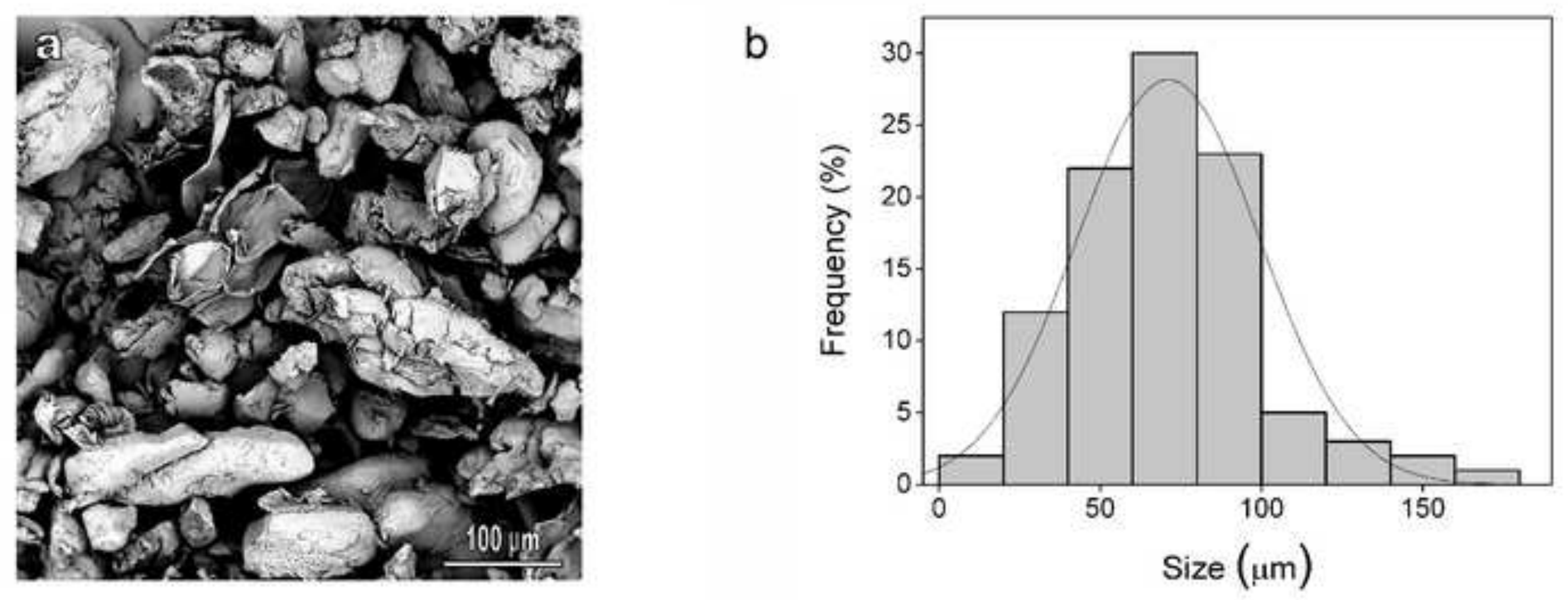


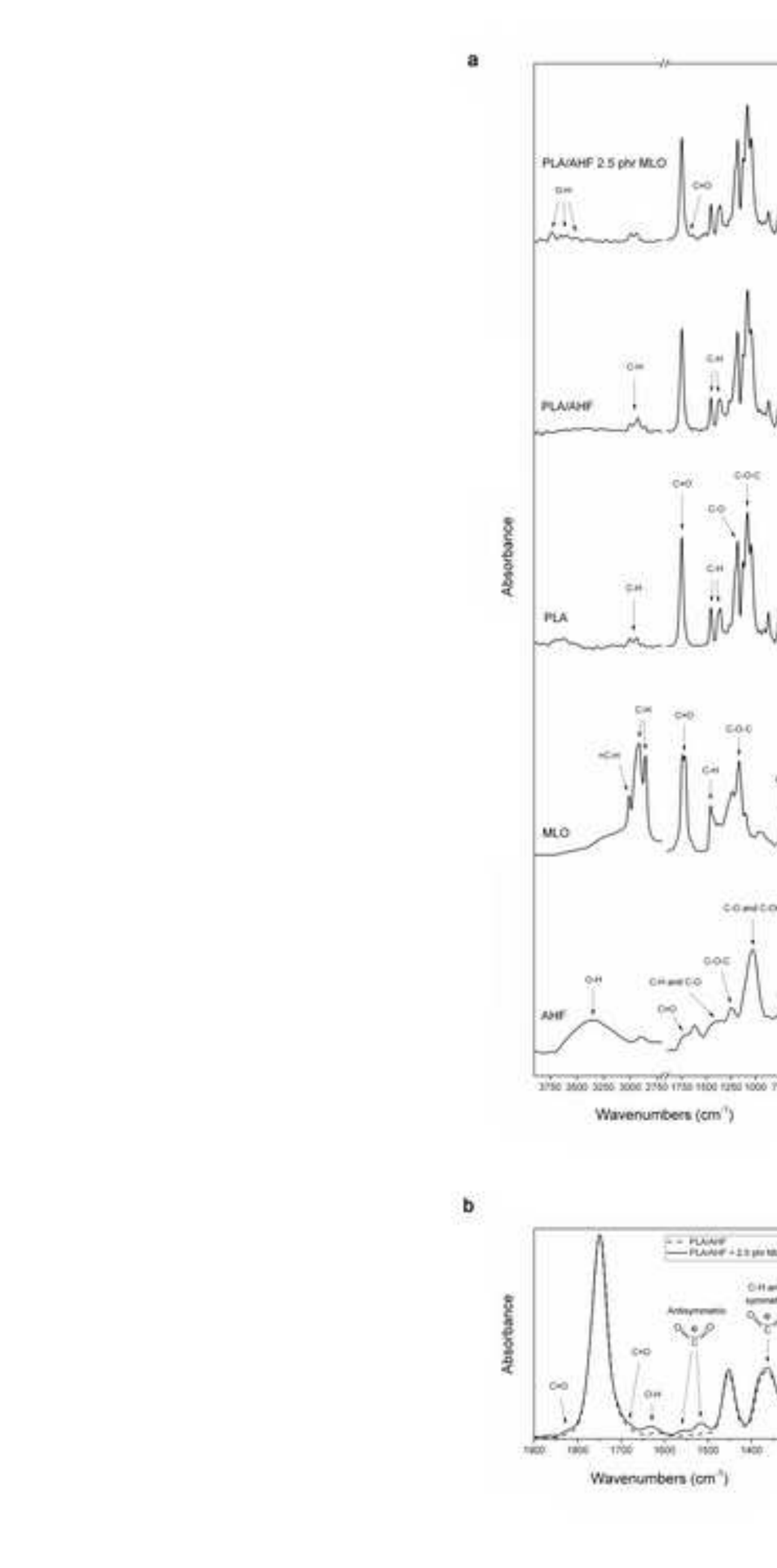

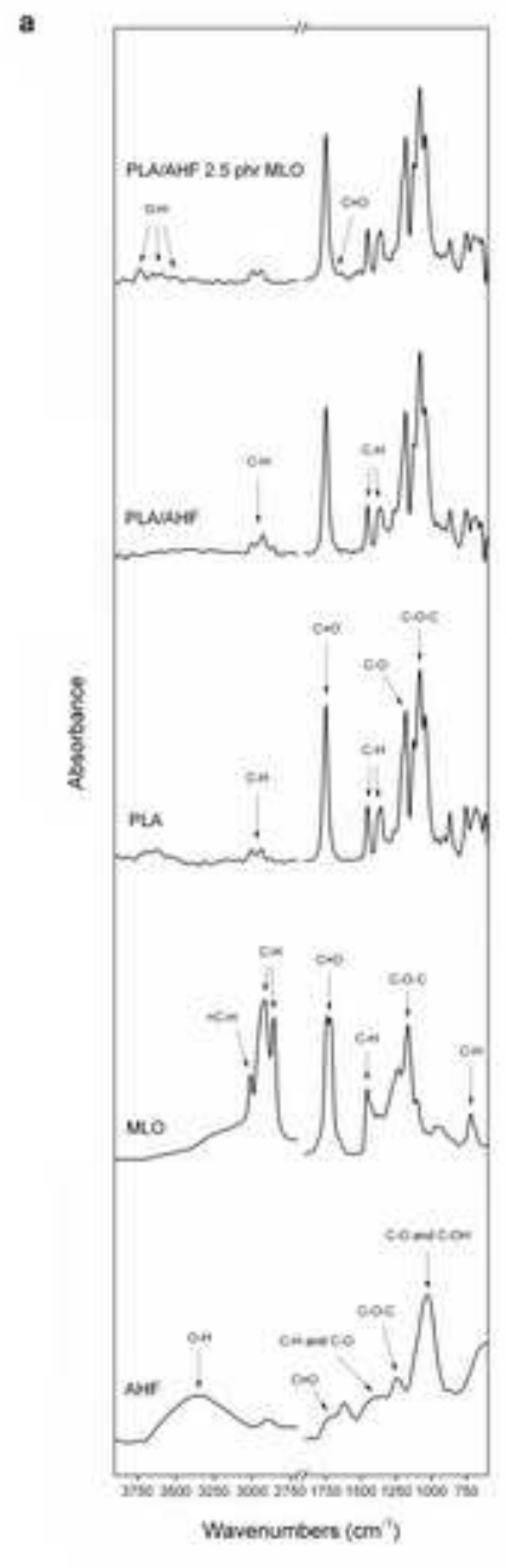

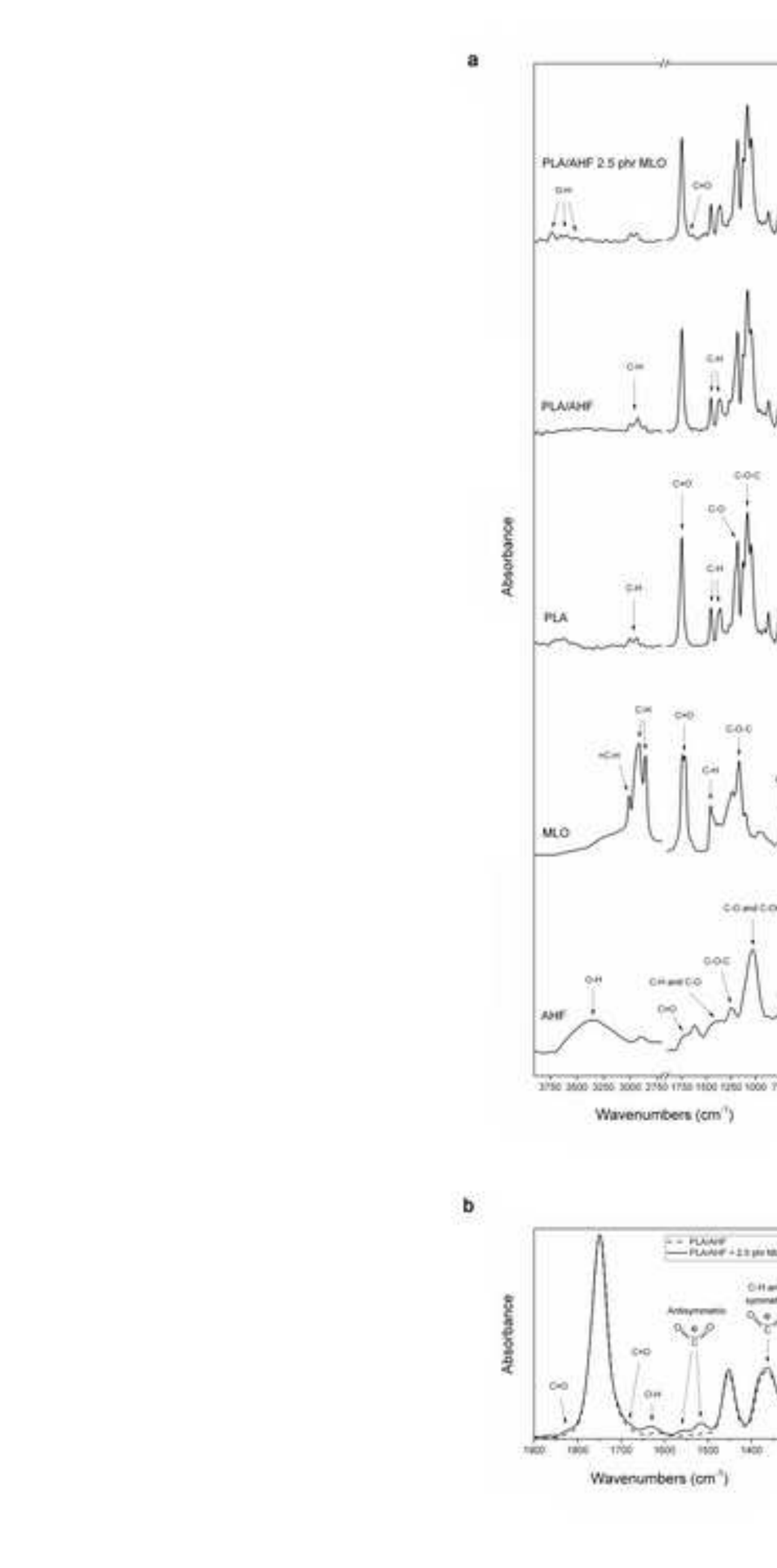

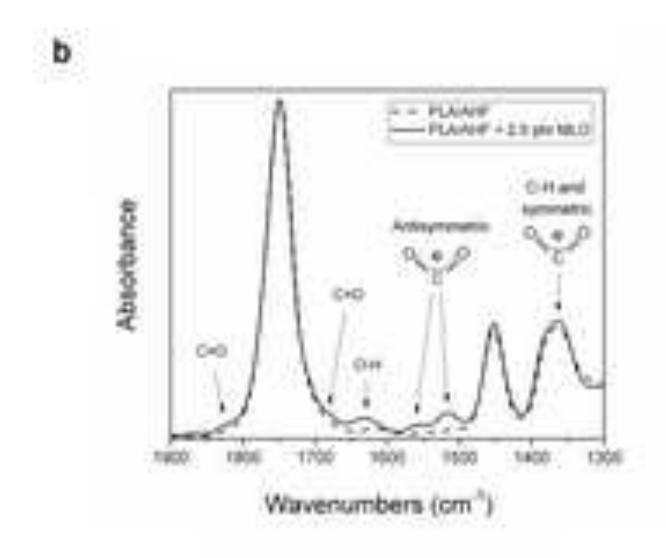

Figure 3

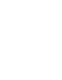
(1)

.

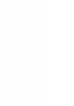

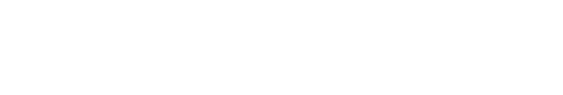


on par on

Almond hask fiour (Ave)
WWH ix malmon

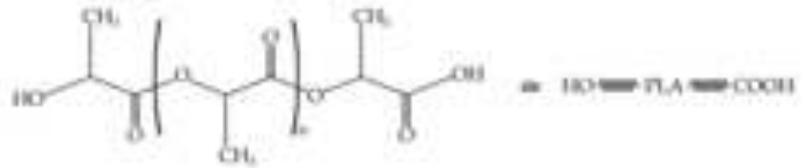

Pesylactise (PLA)

$+$

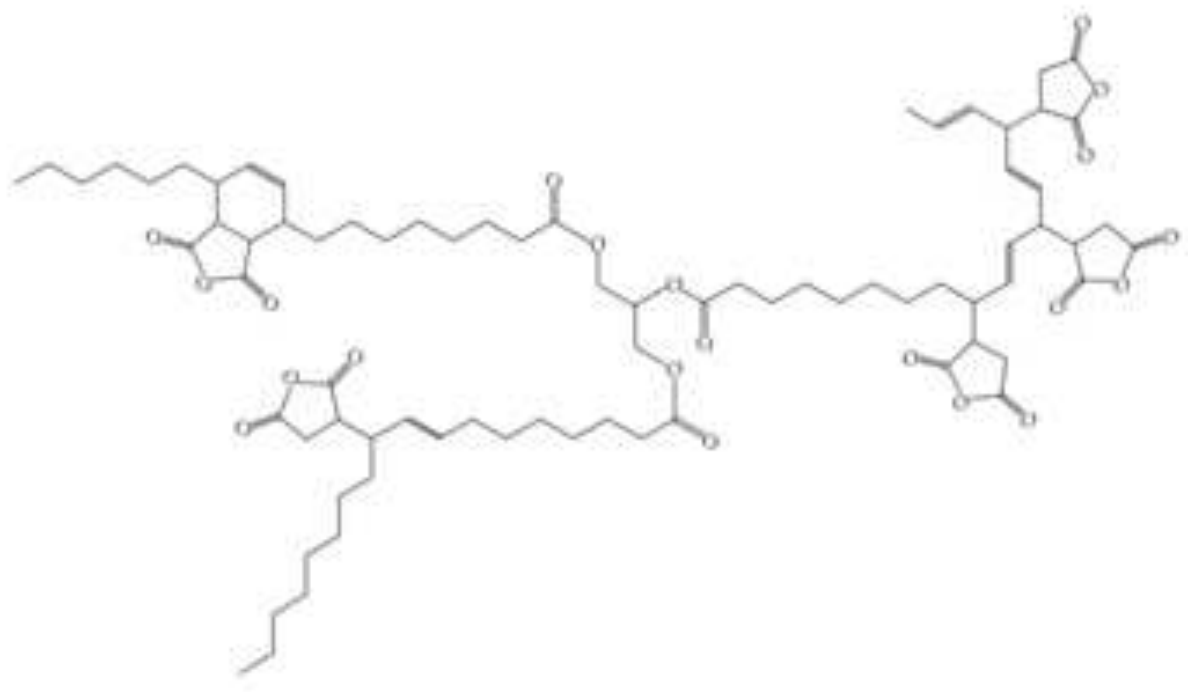

Maleinized inneed of (CEO)

!

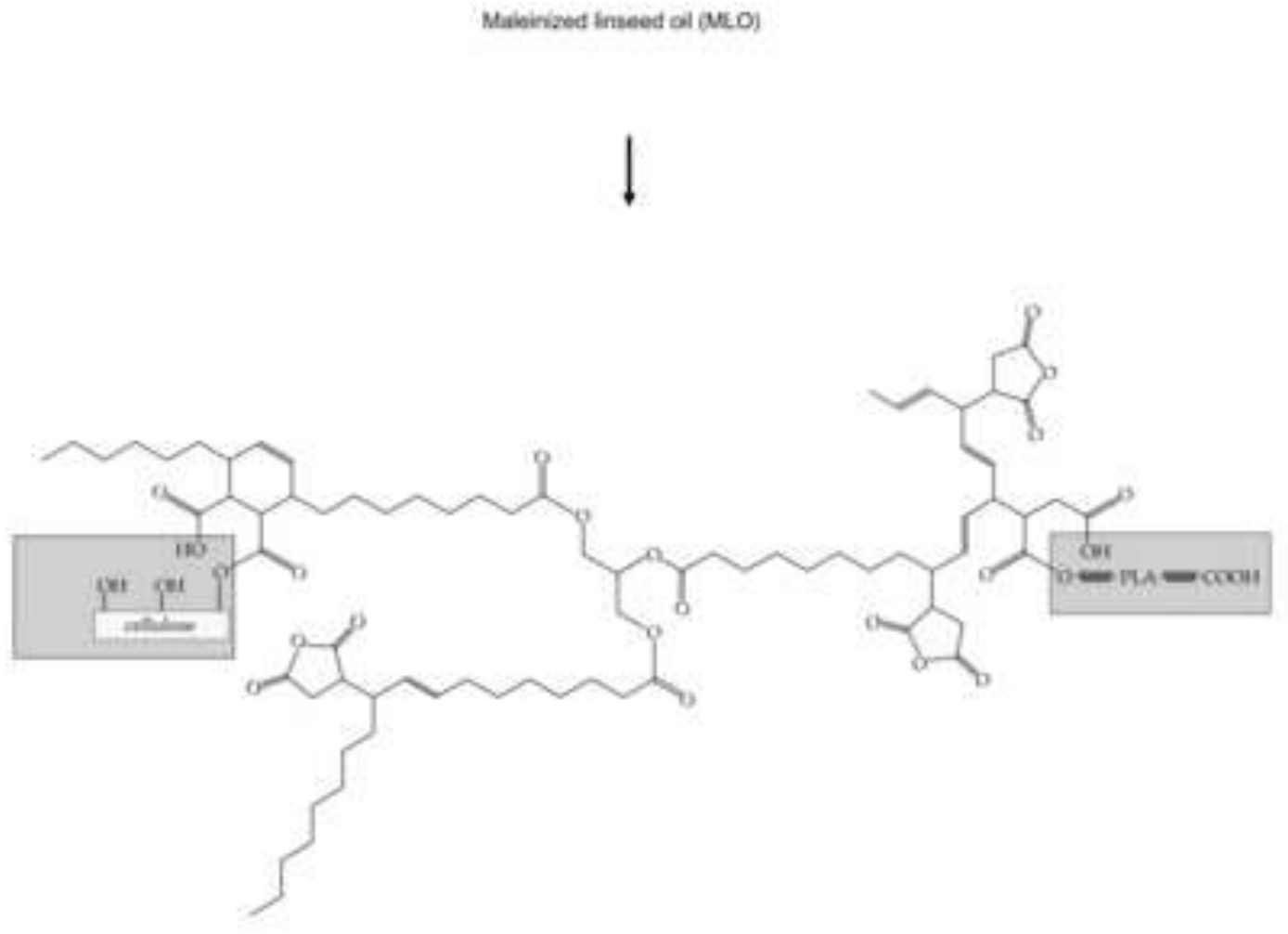

Cethidese-grated PLA icullidose-gPLA)

\section{Figure 4}



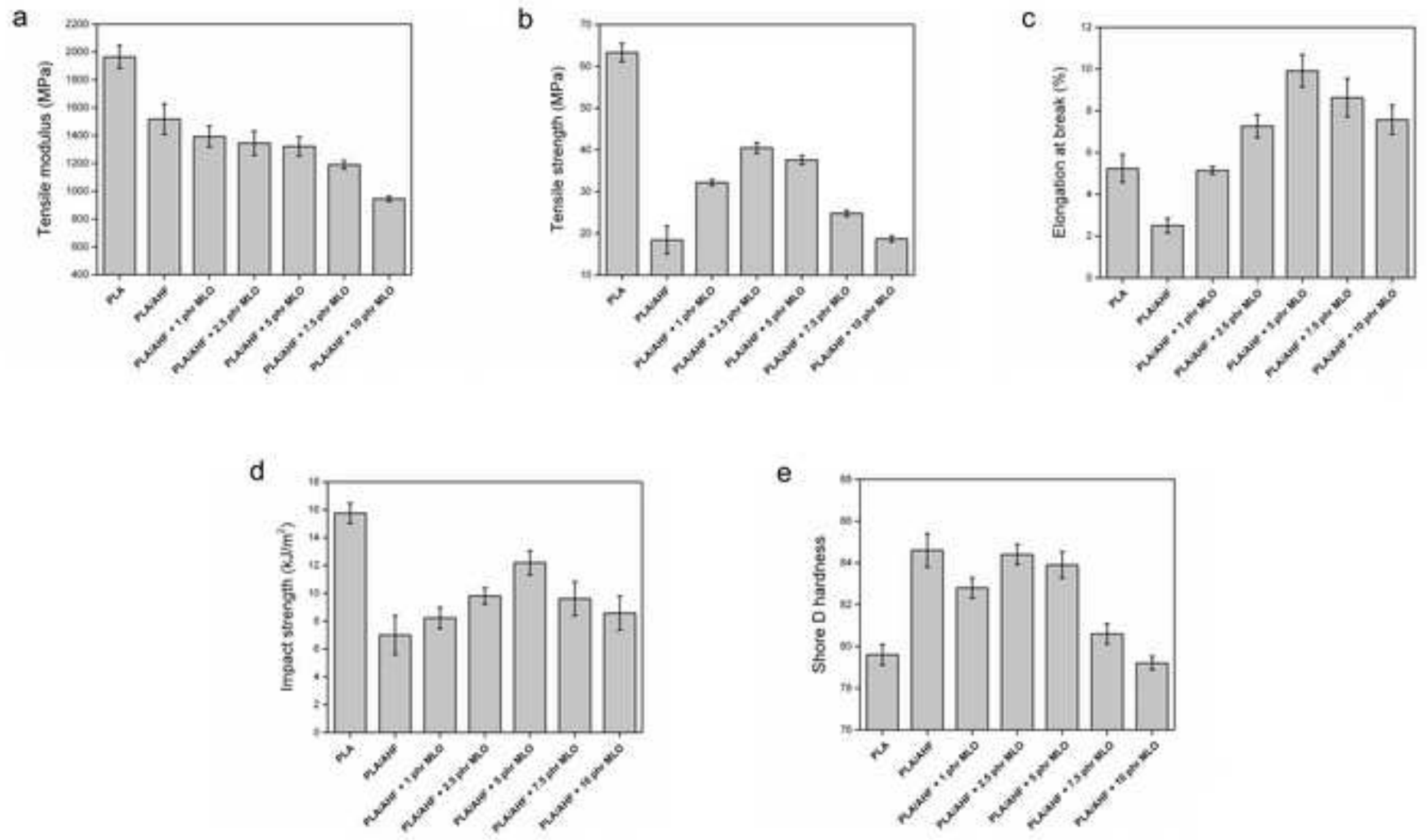

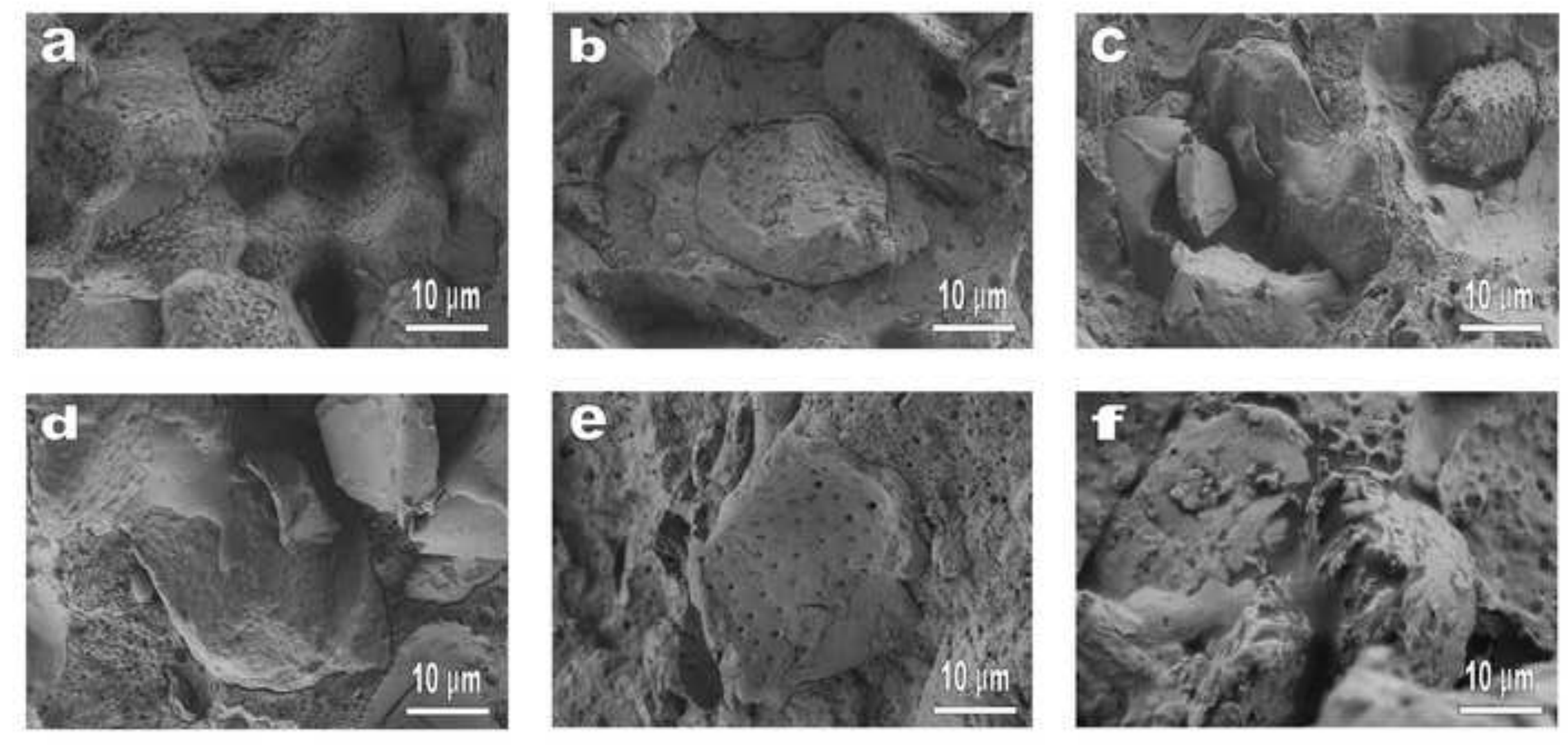